\title{
Interventional Therapies for Chronic Low Back Pain: A Focused Review (Efficacy and Outcomes)
}

\author{
Vikram B. Patel $^{1, *} ;$ Ronald Wasserman $^{2} ;$ Farnad Imani $^{3}$ \\ ${ }^{1}$ Phoenix Interventional Center for Advanced Learning, Algonquin, Illinois, USA \\ 2 Back and Pain Center, University of Michigan, Ann Arbor, Michigan, USA \\ 3 Pain Research Center, Iran University of Medical Sciences, Tehran, Iran \\ *Corresponding author: Vikram B. Patel, Phoenix Interventional Center for Advanced Learning, Algonquin, Illinois, USA. Tel: +1-8478547246, E-mail: vikpatel1@yahoo.com
}

Received: May 4, 2015; Accepted: May 17, 2015

\begin{abstract}
Context: Lower back pain is considered to be one of the most common complaints that brings a patient to a pain specialist. Several modalities in interventional pain management are known to be helpful to a patient with chronic low back pain. Proper diagnosis is required for appropriate intervention to provide optimal benefits. From simple trigger point injections for muscular pain to a highly complex intervention such as a spinal cord stimulator are very effective if chosen properly. The aim of this article is to provide the reader with a comprehensive reading for treatment of lower back pain using interventional modalities.

Evidence Acquisition: Extensive search for published literature was carried out online using PubMed, Cochrane database and Embase for the material used in this manuscript. This article describes the most common modalities available to an interventional pain physician along with the most relevant current and past references for the treatment of lower back pain. All the graphics and images were prepared by and belong to the author.

Results: This review article describes the most common modalities available to an interventional pain physician along with the most relevant current and past references for the treatment of lower back pain. All the graphics and images belong to the author. Although it is beyond the scope of this review article to include a very detailed description of each procedure along with complete references, a sincere attempt has been made to comprehensively cover this very complex and perplexing topic.

Conclusion: Lower back pain is a major healthcare issue and this review article will help educate the pain practitioners about the current evidence based treatment options.
\end{abstract}

Keywords:Low Back Pain; Facet Joint; Sacroiliac joint; Procedures; Intradiscal Procedures, Disc Decompression; Discography; Spinal Cord Stimulation; Interventional Therapies

\section{Context}

Low back pain is one of the most common ailments that bring a patient to a pain specialist. Interventional modalities for low back pain are highly effective when used in conjunction with other adjuvant modalities and performed by properly trained physicians who are not only well versed with the anatomy and physiology of chronic pain but also possess the special skills necessary for performing such delicate procedures. Failure of a patient to respond to an intervention for low back pain can have several variables. Poor patient selection (1), poor patient compliance (2) and poorly performed intervention may be the primary variables.

Use of fluoroscopy has revolutionized the interventional treatments for chronic pain by providing excellent guidance to the needle placement $(3,4)$, as well as recognizing improper placements such as intravascular (using live fluoroscopy or digital subtraction angiography $(5,6)$ imaging) or unintended intrathecal placements of needles and thus avoiding morbidity in the form of injury to the intra-spinal structures including spinal cord, nerve roots and blood vessels.

\section{Relevant Anatomy}

The lumbar spine is a complex structure. It is capable of maintaining dynamic motion of the lower back while bearing the weight of the upper body and torso.

The lumbar spine is composed to five vertebral bodies numbered 1 - 5 from cephalad to caudad direction. The vertebral bodies are separated by the intervertebral discs which provide shock absorbing function as well as flexibility to the lumbar spine (Figure 1).

The lumbar vertebra is formed by the body anteriorly, the pedicles projecting posterolaterally anterolaterally and the laminae projecting posteromedially uniting in the posterior aspect to form the spinous process. The transverse processes arise from the lateral aspect bilaterally. The spine can be divided into anterior, middle and posterior elements for the purpose of diagnosis as well as treatment as depicted in the Figure 2. The anterior segment consists of the vertebral body and the intervertebral disc, anterior and posterior longitudinal ligaments, the gray and white rami communicantes and the sympathetic chain. The middle segment consists of the longitudinal canal and its contents including the spinal cord

Copyright (C) 2015, Iranian Society of Regional Anesthesia and Pain Medicine(ISRAPM). This is an open-access article distributed under the terms of the Creative Commons Attribution-NonCommercial 4.0 International License (http://creativecommons.org/licenses/by-nc/4.0/) which permits copy and redistribute the material just in noncommercial usages, provided the original work is properly cited. 
(up to about L2 level), nerve roots, blood vessels and fatty tissue within the canal and the neural foramina. The posterior segment is made up of the vertebral body arches made up of the pedicles, the transverse processes, the laminae and the articular elements including the facet (zygapophyseal) joints, ligaments and the corresponding nerve and blood supply.

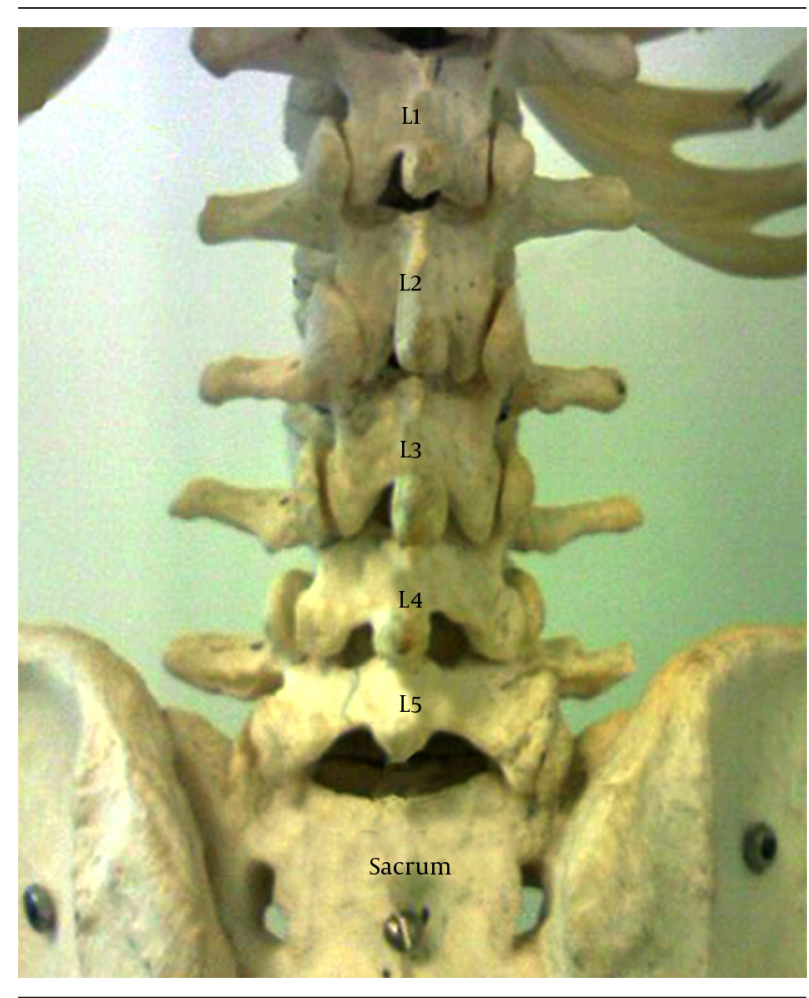

Figure 1. Lumbar Spine Anatomy

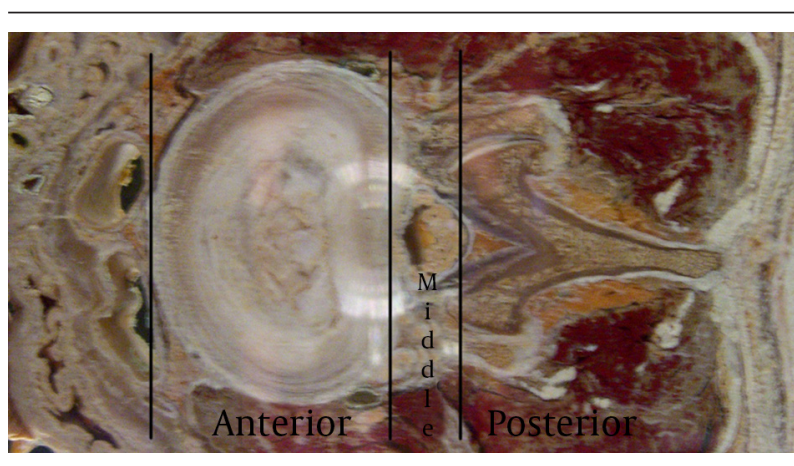

Figure 2. A Cross Section of the Lumbar Vertebral Level Showing the Different Sections of the Spine

\section{Etiology of Low Back Pain}

Lower back pain can arise from multiple structures including the discs (secondary to herniation, internal disc disruption, infection), the vertebral bodies (secondary to vertebral fracture, infection, metastatic lesion), lumbar nerve roots (compression due to mechanical causes from a herniated disc or inflammation, spinal stenosis and tethering due to post-surgical scarring), lumbar facet joints (degeneration, inflammation, injury), muscular components from the muscles attached to the ,lumbar spine and the iliac crest, ligaments and the sacroiliac joint. Multiple conditions may involve more than one pain generators. Such conditions include scoliosis, kyphosis, spondylolisthesis, metastasis, post-laminectomy syndromes, trauma etc.

Pain may also radiate posteriorly to the spinal area from the abdominal viscera such as the aorta, the pancreas, ovaries, intestines, kidneys etc. and such causes should be ruled out with appropriate imaging studies (7-9).

\section{Interventions}

\subsection{Basic Interventions}

\subsubsection{Trigger Point Injections}

Trigger point injections are the most basic of interventions which are known to help with myofascial pain (10, 11) in selected patients. Various practitioners have used different types of medications and/or combinations of different pharmaceutical agents (such as local anesthetic and steroid, local anesthetic/steroid/opiate, botulinum toxin (Botox) $(12,13)$ etc.). Some medications such as Sarapin $®$ (an extract from pitcher plant) are widely used but do not have much supporting literature to be recommended for such usage (14). "Dry needling" is also a technique used by many $(15,16)$ and is shown to be equally effective as local anesthetic when combined with physical therapy. A common practice is to inject the affected muscle at various points detected on palpation to be the most tender (signifying the trigger points) using a small bore needle (27G) and about 2 - $4 \mathrm{~mL}$ of injectate. Immediate relief is apparent in most cases. The injections themselves may not provide long term relief and hence have to be combined with proper stretching exercises which are the main modalities to help achieve long term pain relief.

\subsubsection{Epidural Steroid Injections}

Epidural steroid injections have been used for past several decades (17-19) for multiple indications for the lower back pain (20). Initially the injections were performed blindly without the use of imaging guidance but the recent concerns of vascular injections (especially with particulate steroids) have prompted a recommendation for the use of fluoroscopic or CT guidance for these injections $(21,22)$. Even in experienced hands blind epidural steroid injections result in inaccurate needle placement in up to $30 \%$ of cases (White AH, Derby R, Wynne G Epidural injections for the diagnosis and treatment of low-back pain. Spine 1980; 5:67-86, White AH Injection techniques for the diagnosis and treatment of low back pain. Orthop Clin North Am 1983; 14:553-567). Aberrant injections can occur into the multifidus muscle, subdural or subarach- 
noid space. In addition intravascular injection can occur with an incidence of $0.5 \%$ in the lumbar region to $4 \%$ in the thoracic region. Various approaches have been used over the years for these injections $(18,20)$.

\subsubsection{Lumbar Interlaminar Epidural Injection}

This is the most common approach that is utilized for "blind" injections. It utilizes a "loss of resistance to air" (or fluid or air/fluid interface) technique to recognize the penetration of the ligamentum flavum and thus into the epidural space. This technique has been used for a long time for placement of epidural catheters for labor analgesia, post-operative analgesia etc. However, for a single shot injection it is advisable to use fluoroscopic guidance not only for proper placement of medication at the right level but also on the right (correct) side and more importantly to avoid any vascular injection, the incidence of which was found to be between $0.5 \%$ in the lumbar region to $4 \%$ in the thoracic region (23). Injection of a water soluble contrast medium is required to confirm proper placement of the needle. A live injection of contrast under fluoroscopic view is recommended to recognize intra-vascular uptake. Digital Subtraction Angiography (DSA) has been considered the gold standard for recognition of intravascular spread of the contrast material. Of course it can also help one recognize an intra-thecal or sub-dural injection as well.

\subsubsection{Technique}

The approach is usually midline or slightly paramedian towards the site of the pathology. The fluoroscopic view can be used to determine the appropriate level of the in- jection between the vertebral spinous processes. An epidural needle (usually an 18 G or 20 G 3.5" Touhy needle) is utilized for accessing the epidural space. Once the needle is within the interspinous ligament, a glass or plastic "loss of resistance" syringe is attached to the needle. The needle is then gradually advanced through the interspinous ligament until a distinct "pop" is felt and there is a loss of resistance to injection through the attached syringe. The fluoroscopic view when used in a lateral projection or a contra-lateral oblique projection would also confirm the placement of the needle tip within the posterior aspect of the epidural space (Figure 3). A confirmatory injection of water soluble contrast medium is then carried out under live fluoroscopy to obtain an epidurogram. Once confirmed, the main injectate usually comprises of a mixture of local anesthetic/normal saline and the intended cortico-steroid, is injected gradually. Adding normal saline or local anesthetic to the mixture helps create adequate volume for better coverage of the inflamed areas (Figure 3).

\subsubsection{Evidence}

As one of the oldest technique for epidural injections, it has been studied extensively. Its use for chronic low back pain is also one of the oldest treatments for this ailment. In one of the recent randomized, double-blind, activecontrol trial studies, Manchikanti et al. (24) found that lumbar interlaminar epidural injections of local anesthetic with or without steroids might be effective in patients with disc herniation or radiculitis, with potential superiority of steroids compared with local anesthetic alone at 1 year follow-up. In a systematic review for lumbar interlaminar epidural injections, Benyamin et al. (25)
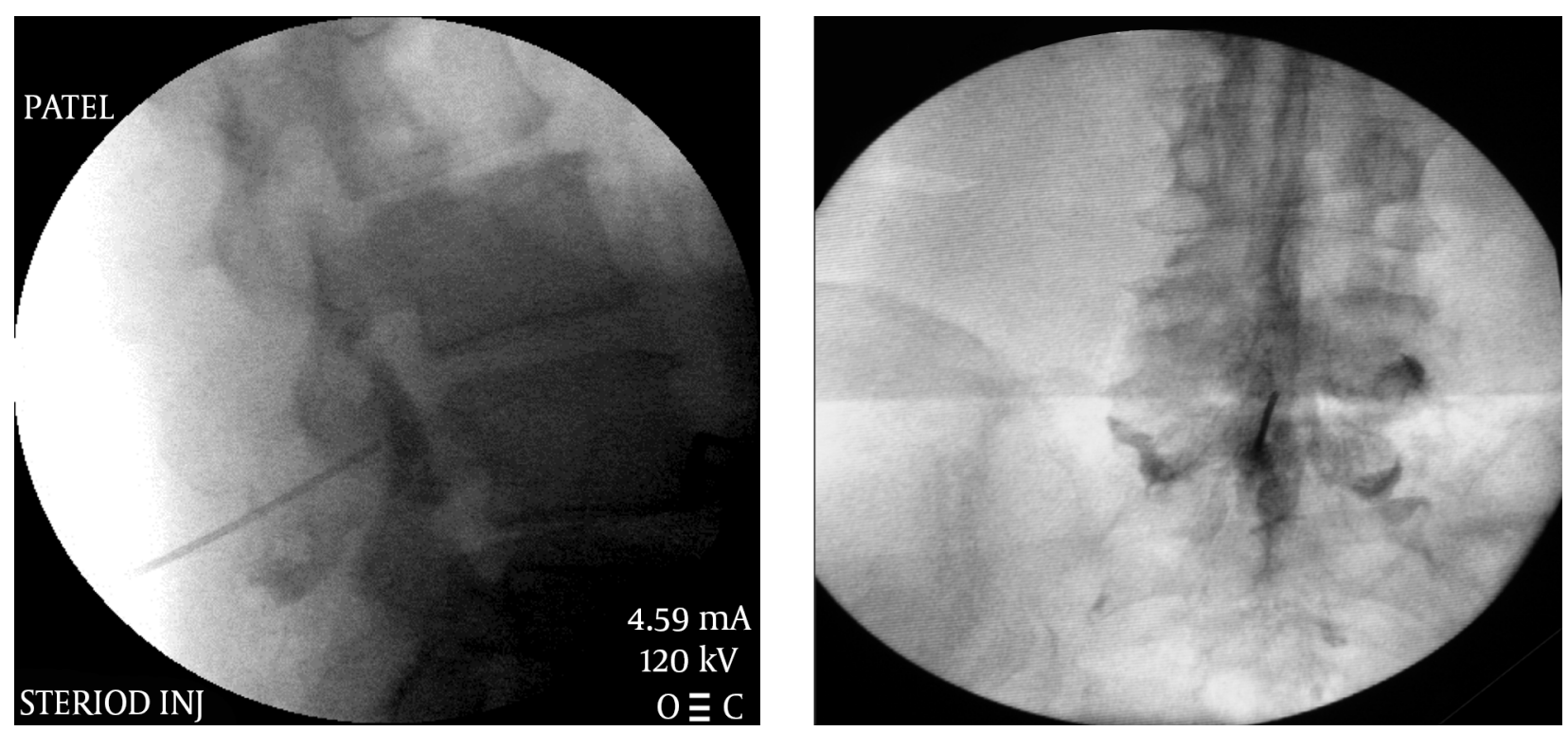

Figure 3. Lumbar Interlaminar Epidural Injection AP and Lateral Views 
concluded that the evidence was good for lumbar epidural injections under fluoroscopy for radiculitis secondary to disc herniation with local anesthetic and steroids, fair with local anesthetic only; whereas it was fair for radiculitis secondary to spinal stenosis with local anesthetic and steroids, and fair for axial pain without disc herniation with local anesthetic with or without steroids.

\subsubsection{Caudal Epidural Injection}

Also one of the most common injections in the treatment of lower back pain, in the past a caudal approach was usually performed without any fluoroscopic guidance using just the palpable anatomical landmarks. However it was later realized that a blind caudal injection does not have a reliable way of entering the caudal epidural space and hence it is now mainly performed using fluoroscopic guidance (26).

This technique is especially useful in patients who have a post-surgical spine and those with severe lumbar degeneration or stenosis and have a difficult to access epidural space using midline interlaminar lumbar approach.

\subsubsection{Technique}

Caudal approach to the epidural space is best accomplished using a lateral view on the fluoroscope. The sacral hiatus can be easily visualized on a lateral view following the posterior border of the sacrum, however it may also be absent in a small percentage of patients (27). In some patients there may be a deficient posterior wall as well (28), and the incidence of deficiency is found to be higher in patients with low back pain (29). Sacral shapes are varied in human beings. Females usually have a "C" shaped sacrum while males normally have a "J" shape. An epidural needle is recommended for accessing this sacral epidural space. Once inside the sacral canal (epidural space) the needle tip is halted at about S3 level to avoid penetration of the dura which usually extends up to the $\$ 2$ level but can be lower. A midline approach is normally attempted and is easier to visualize following the natal cleft. Needle may be directed slightly laterally to either side depending on the pathology and intended side of the epidural space. After confirming the epidural placement utilizing a small amount of contrast, the cortico-steroid can be injected. An epidurogram is performed by most physicians to evaluate the extent of pathology and the spread of the injectate. A larger amount of injectate is usually required when using a caudal approach to effectively reach the level of pathology $(30,31)$. The caudal canal contains a large amount of venous plexi and intra-vascular placement of the needle tip is not uncommon (32), hence it is important to identify the placement with an injection of water soluble contrast media (Figure 4).

\subsubsection{Evidence}

Caudal epidural steroid for lower back pain especially in patients with spinal stenosis has been known to be effective. In a recent extensive systematic review of literature, Parr et al. (33) found that the evidence was fair for caudal epidural injections in managing chronic axial or discogenic pain, spinal stenosis, and post-surgery syndrome, however it was good for short- and long-term relief of chronic pain secondary to disc herniation or radiculitis with local anesthetic and steroids. They also noted that it was more effective than transforaminal as well as interlaminar approaches. In an earlier review, Conn et al. (34) had found that there was a Level II-1 or II-2 evidence for caudal epidural injections in managing chronic pain of post lumbar laminectomy syndrome and spinal stenosis. In a randomized trial Manchikanti et al. (20) found that caudal epidural injections of local anesthetic with or without steroids were effective in patients with chronic axial low back pain of discogenic origin without facet joint pain, disc herniation, and/or radiculitis.

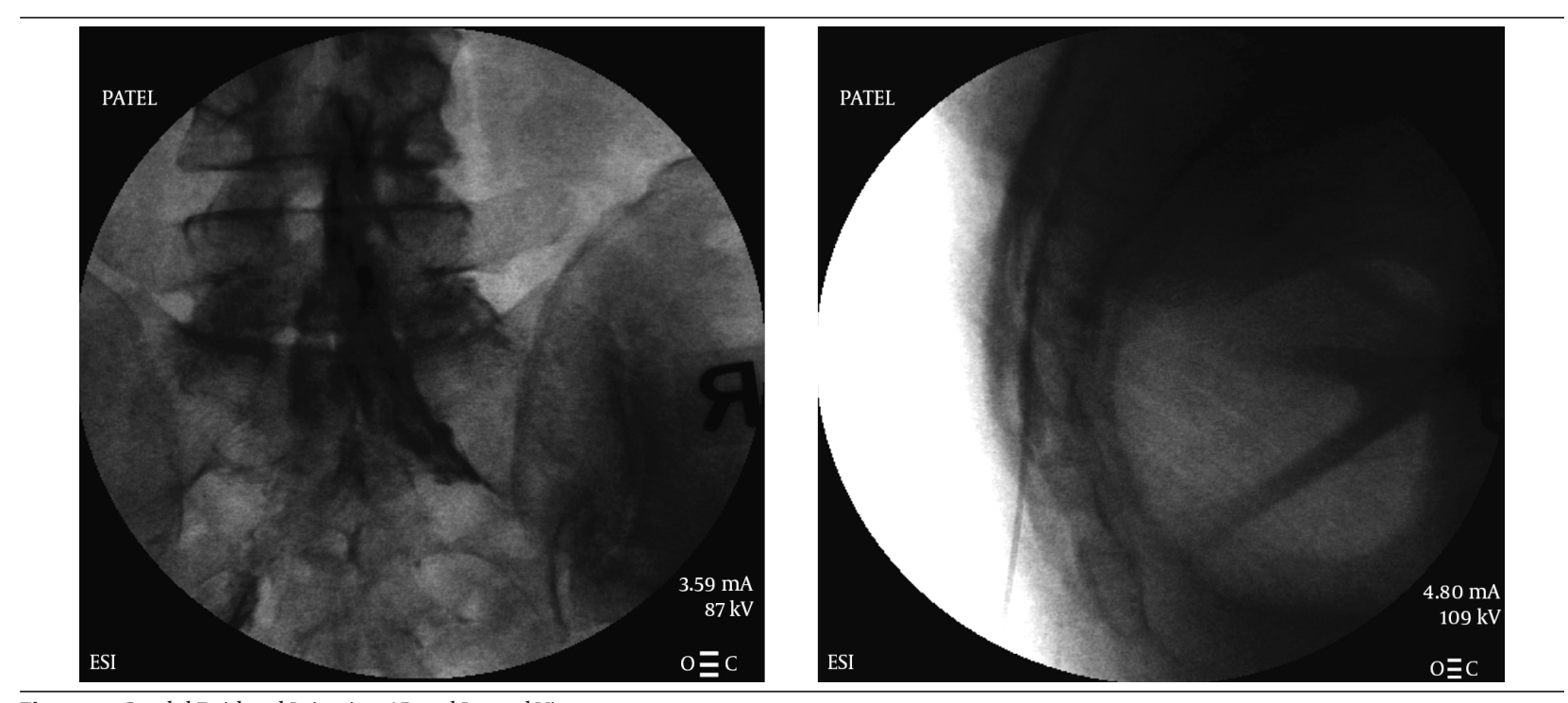

Figure 4. Caudal Epidural Injection AP and Lateral Views 


\subsubsection{Transforaminal Epidural Injection}

A Transforaminal approach to injecting a steroid into the lumbar spine is mainly used for a nerve root inflammation which is the cause of radicular symptoms allowing a peri-neural coverage $(35,36)$. Although these symptoms are usually presented as radiating pain to the lower extremity, in most cases there is also a lower back pain component. This is mostly due to the damage to the intervertebral disc but can also be due to the referral pattern of an inflamed nerve root. They have been shown by some studies to be superior to the inter-laminar approach (37). Hence this approach is also mentioned here for the sake of completeness.

The approach to the intervertebral foramen is accomplished from a postero-lateral angle under fluoroscopic guidance (Figure 5). The technique initially involved placement of the needle tip inferior to the corresponding pedicle inside the spine. However, even if the needle tip is at the rim of the intervertebral foramen, the medica- tion has been shown to cover the intended areas very well thus reducing the chances of any damage to the dura or the nerve roots (38). More recently it has been advocated by some that placing the needle in the inferior aspect of the foramen reduces the risk of nerve root damage as well as penetration of any arterial component within the foramen. An approach to this space via the inferior aspect of the foramen (supra pedicular, retro-discal (39)) (Figure 6 ) is described through the so called "Kambin's triangle" $(40,41)$. Some physicians prefer to advance the needle up to the anterior epidural space which is unnecessary as the injectate can be deposited in the vicinity of the pathology even with the tip of the needle in the postero-lateral aspect of the foramen (42). If the needle is advanced too far it has been known to enter the disc $(43,44)$ which is usually protruding in most cases that need treatments. This may theoretically lead to higher incidence of disc infection if due precautions are not taken.
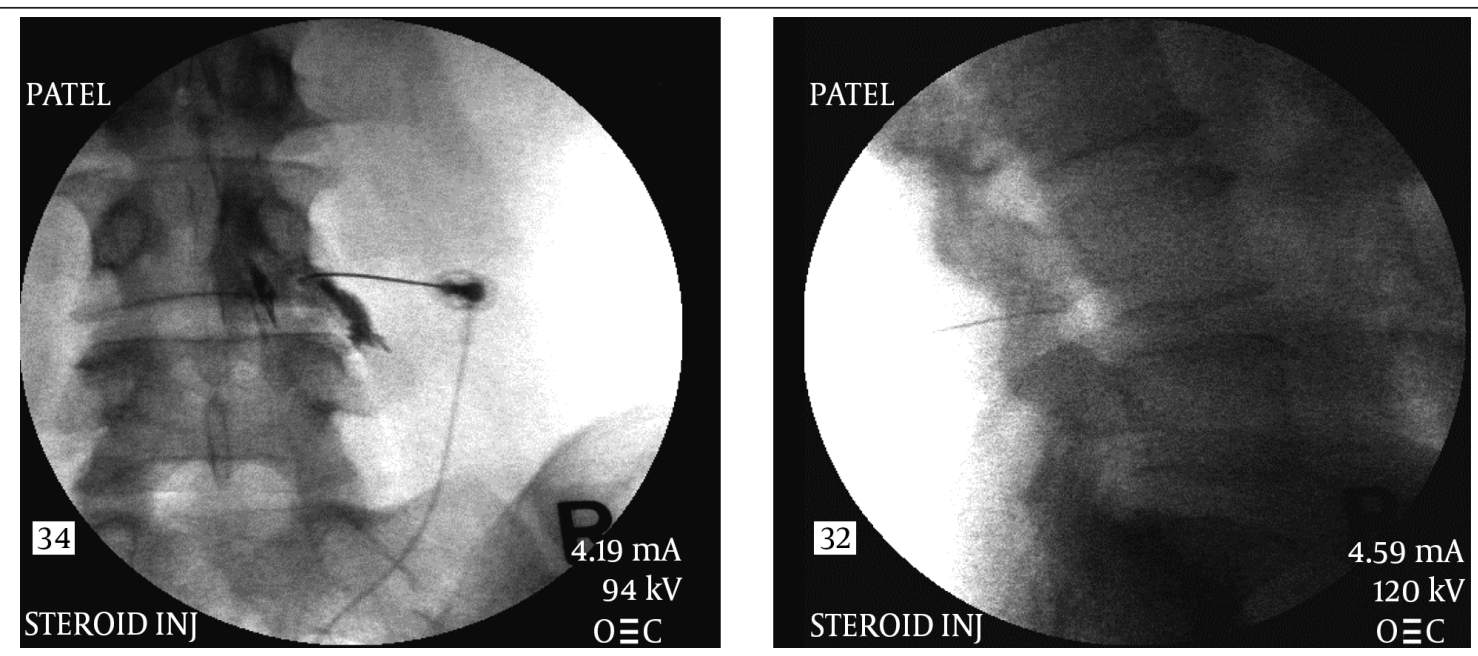

Figure 5. Transforaminal Injection AP and Lateral Views; Infra-Pedicular Approach
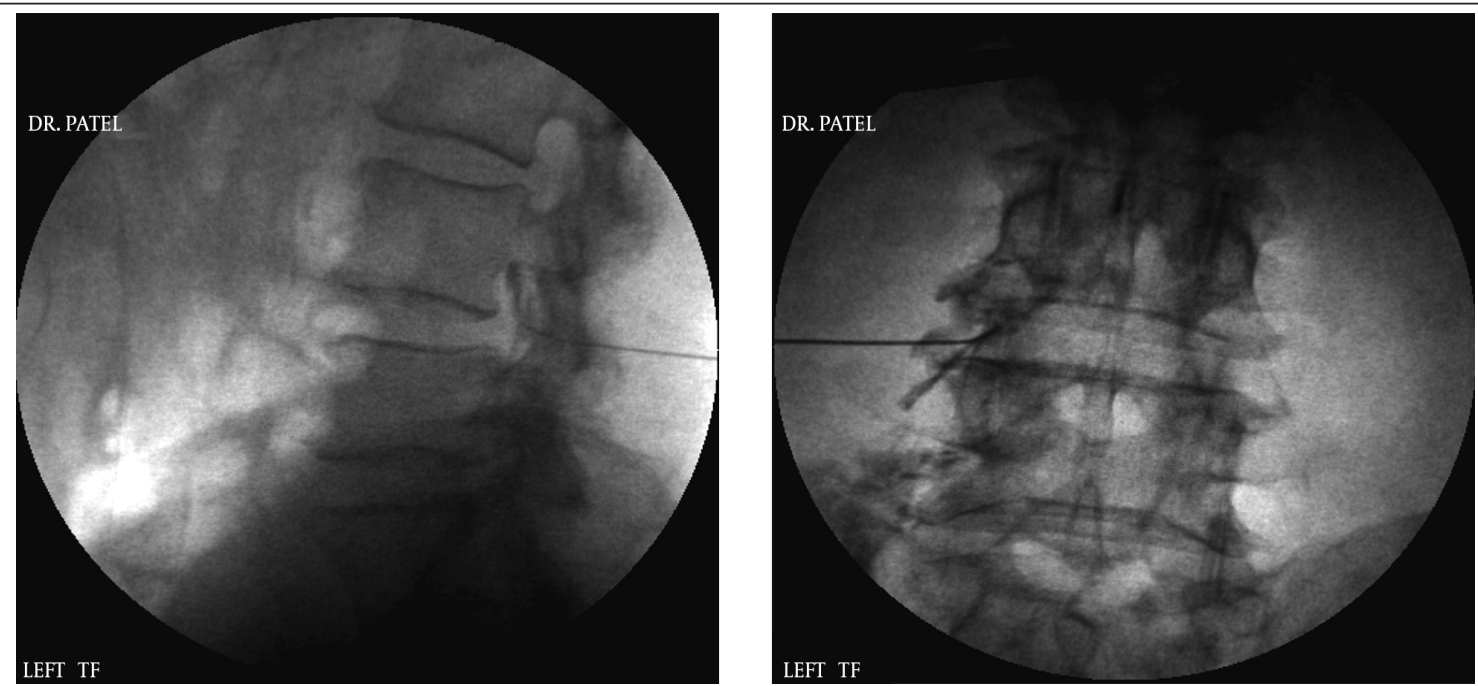

Figure 6. Transforaminal Injection AP and Lateral Views; Supra-Pedicular Approach 


\subsubsection{Evidence}

The evidence for transforaminal injections just for lower back pain without radicular component is not very strong. However, this route has been used for administration of steroids for decades. Most of the studies conducted, included lower back pain with radicular pain. However, considering the disc as a source of lower back pain as well as radicular pain several studies have suggested transforaminal injections prior to consideration of a surgical intervention. Lutz et al. (45) concluded in a study published in late 90 s that fluoroscopic transforaminal epidural steroids are an effective nonsurgical treatment option for patients with lumbar herniated nucleus pulposus and radiculopathy in whom more conservative treatments are not effective and should be considered before surgical intervention. In a focused review of transforaminal epidural injections, Manchikanti (46) suggested that the indications and evidence in favor of therapeutic transforaminal epidural steroids in managing chronic low back pain are balanced and less controversial than diagnostic blocks and other means of administration of epidural corticosteroids, namely, blind interlaminar epidural injections.

\subsection{Facet Joint Interventions}

Facet joints are the most common pain generators in the lumbar spine (47) representing anywhere from $15 \%$ to $45 \%$ of low back pain. Joint degeneration leadeing to facet joint hypertrophy, soft tissue infolding and osteophyte formations (48) is the most common cause of pain but other causes such as trauma, synovial cyst, spondylolisthesis etc. are also known to cause facet joint syndrome. In a post-surgical spine, the levels above and below the surgical (fusion) level are the most common sources for pain (49). Pain is usually felt with extension and/or rotation of the lumbar spine especially in older population making it less painful for the patient to bend forward while being upright. Although a reliable history and physical examination and radiological findings of degeneration can provide enough suspicion for these pain generators, a diagnostic block under fluoroscopic guidance is considered to be the most reliable diagnostic test $(50,51)$ and the evidence for such blocks is Level I or II-1.

Once diagnosed, this type of pain can be treated with steroid injections into the intra-articular area, or by ablation of the nerves supplying these joints thus making them insensate (50).

\subsubsection{Medial Branch Block}

The facet joints are supplied by the medial branches of the dorsal ramus of a spinal nerve root (Figure 7). At any given level, a facet joint is supplied by two medial branches, one from the same level and one from the level above in case of a lumbar facets (51). Thus the L4-5 facet joint is supplied by the medial branches of L4 as well as L3 nerve roots. These medial branches lie in close proximity to the bone at the junction of the transverse and superior articular processes. The medial branch from the nerve root at any given level lies at this junction of the lower level. Thus the L5 medial branch (essentially the dorsal primary ramus) lies over the junction of superior articular process and the ala of the sacrum and the L5 transverse process houses the L4 medial branch (52).

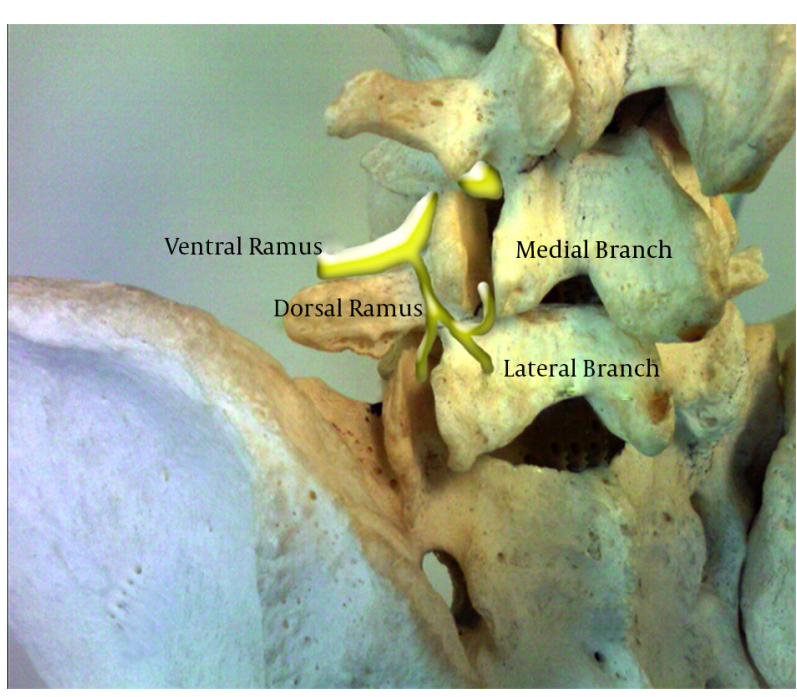

Figure 7. Lumbar Spine Anatomy Showing the Medial Branches

\subsubsection{Technique}

An oblique view is necessary to visualize this junction which is then superimposed over the pedicle at that level. In a classic view depicting a "Scotty dog" image, this point corresponds to the eye of the "Scotty" (Figure 8). For a diagnostic block of the medial branch a very small amount of local anesthetic is advocated and usually $0.5 \mathrm{~mL}$ of local anesthetic is sufficient (51). Higher amount may lead to a false positive response. The placement of the needle is confirmed by injecting a very small amount of contrast medium which usually shows the spread along the groove formed by the junction of the transverse and superior articular processes providing an image in oblique view that looks like a blindfold across the "Scotty dog's" eyes (Figure 9). A single needle technique to block multiple levels has been advocated by some $(53,54)$ when it was found that it takes less time, causes less patient discomfort and provides the same accuracy as multiple needle technique. Ultrasound has also been utilized for facet joint medial branch blocks with about the same accuracy as the fluoroscopically guided blocks, confirmed with a computed tomography scan (55). 


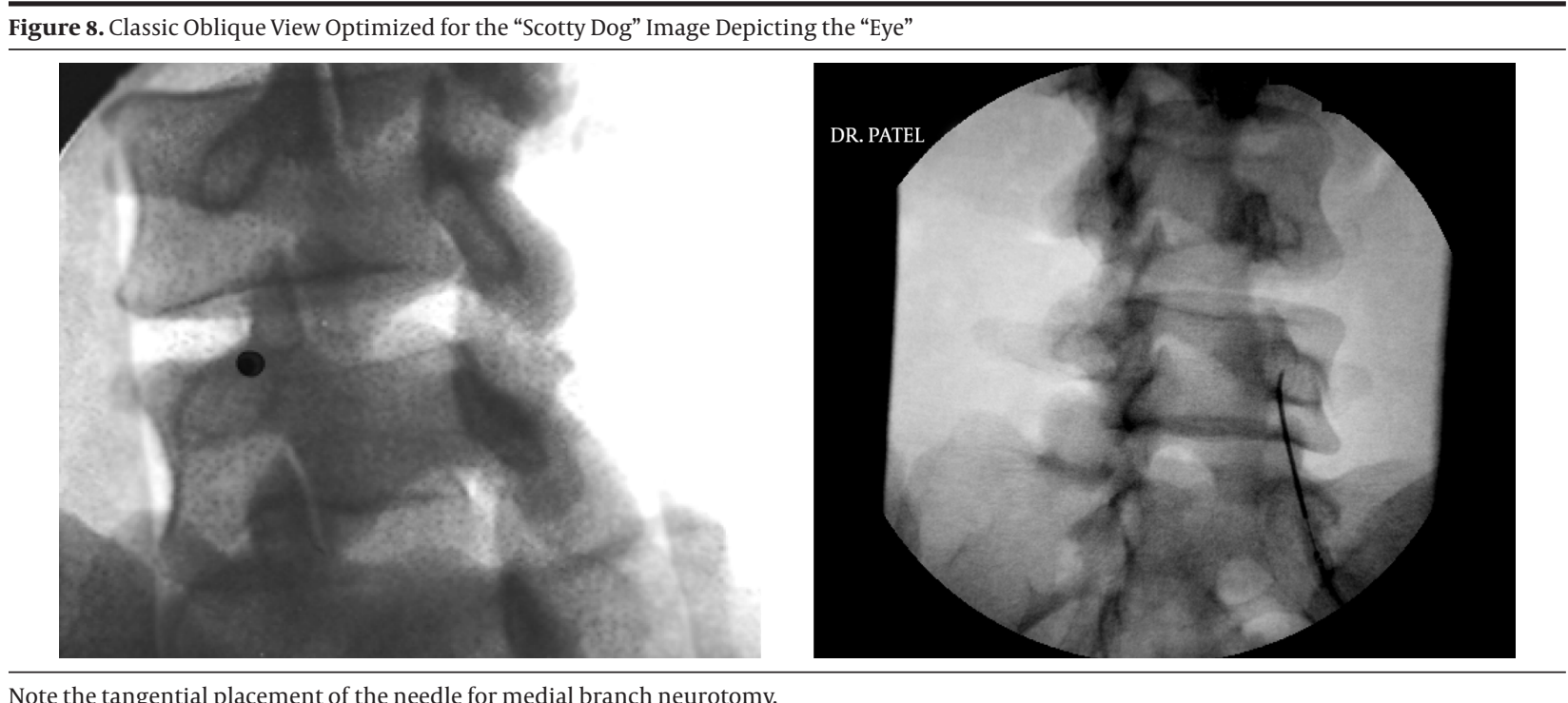

Note the tangential placement of the needle for medial branch neurotomy.
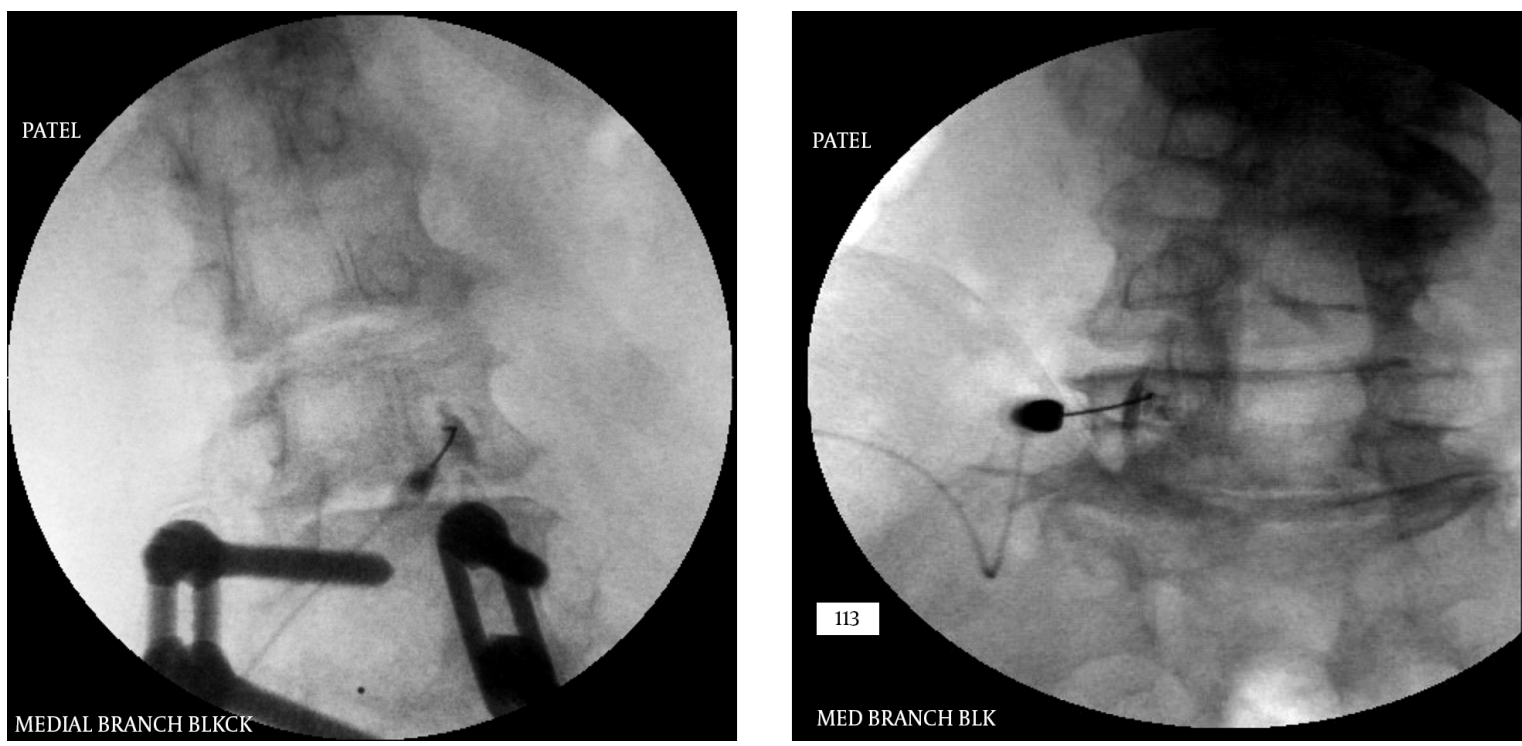

Figure 9. Contrast Spread for Medial Branch Block

\subsubsection{Evidence}

The diagnostic rather than therapeutic nature of medial branch blocks should be kept in mind. For a radiofrequency ablation of the medial branches used in treatment of lumbar facet joint pain, it is necessary to properly diagnose the pain generator as the lumbar facet(s) to achieve the best outcome. The specificity of lumbar medial branch block technique was compared to CT in a cadaveric study by Dreyfuss et al. (56). He noted that "when the appropriate technique is used, medial branch blocks are target specific".

In the past, Manchikanti et al.(57) looked at the validity of lumbar diagnostic medial branch blocks. They concluded that comparative local anesthetic blocks to diagnose lumbar facet joint pain withstood long-term follow-up in $75 \%$ to $85 \%$ of the patients with accurate diagnosis and that they are similar or superior to other well established investigations. In a systematic review of literature studying diagnostic utility of medial branch blocks, Sehgal et al. (58) concluded that controlled comparative local anesthetic blocks of facet joints (medial branch or dorsal ramus) are reproducible, reasonably accurate and safe and that there is strong evidence for controlled comparative local anesthetic facet joint injections or medial branch blocks in the diagnosis of neck and low back pain and moderate evidence in the diagnosis of pain arising from thoracic facet joints. Datta et al. (50) found that the evidence for diagnostic procedures for lumbar facet joint pain with controlled local anesthetic blocks is Level I or II-1. 


\subsubsection{Intra-Articular Facet Joint Injections of Steroids}

Intra-articular injection of steroids for lumbar facet joint (Figure 10A) related pain has recently been losing favor amongst the pain physicians while radio-frequency ablation has gained more acceptance probably because of the evidence available at this time, which found limited evidence for intra-articular injections and fair to good evidence for radio-frequency neurotomy (59). Even so, many physicians still perform this procedure in select cases. For example a patient who is not a candidate for radiofrequency due to a pace-maker or a spinal cord stimulator.

\subsubsection{Technique}

The image guidance for the intra-articular space remains essentially the same as medial branch block, although the obliquity and cephalo-caudad angulations may vary depending on the target level. The needle is advanced within the facet joint after the view is optimized similar to the medial branch block. A curved needle helps steer the tip of the needle into the intra-articular space with ease and single pass through the tissue. A small amount of contrast is injected to confirm the placement. Usually less than $0.5 \mathrm{~mL}$ is injected. Sometimes the contrast may spill over into the epidural space from the joint capsule through a pars interarticularis defect, capsular foramina or a burst capsule and even into an adjacent facet joint $(60,61)$ which may be present in some individuals (Figure 10B). The amount of steroid injected should also be minimal as the joint (especially an inflamed joint) does not have much space which normally has a capacity between 1 to $1.5 \mathrm{~mL}$. About $10 \mathrm{mg}$ of methylprednisolone or equivalent steroid is injected.

\subsubsection{Evidence}

As mentioned before, intra-articular injections for lumbar facets do not have strong evidence. In a systematic review, Datta et al. (50) noted that there was a level III (limited) evidence for intra-articular injections. This was recently reinforced by Falco et al. (59) in 2012. CT guidance for lumbar facet joint injections has also been studied for therapeutic as well as diagnostic utility. Schleifer et al. (62) found that CT-guided facet joint infiltration is a good method for treatment and diagnosis of lumbar facet joint syndrome. Similarly, ultrasound (U/S) guidance has also been recently promoted extensively for lumbar facet joint interventions. Yun et al. (63) found that U/S-guided injections in patients with lumbar facet syndrome are as effective as fluoroscopically guided injections for pain relief and improving activities of daily living. After studying the effectiveness of lumbar facet joint injections as well as radio-frequency denervations, it has been recommended by Civelek et al. (64) that the first choice should be the facet joint injection and if the pain reoccurs after a period of time or the injection is not effective, radio-frequency procedure should be used for the treatment of chronic lumbar pain. They noticed that over short term, the joint injection was more effective than radio-frequency. However in midterm follow-up radio-frequency had more satisfying results.

\subsubsection{Radiofrequency Ablation of the Medial Branches}

A successful medial branch diagnostic block is followed by radio-frequency ablation of the same medial branches. As mentioned previously, for a diagnostic injection, a very small amount of local anesthetic is injected at each level of the medial branch block to avoid any spillage of the local anesthetic into the epidural space, which may provide a false positive result. The duration of pain relief has to correspond to the type of local anesthetic injected. It may be advisable to perform the diagnostic medial branch blocks twice using different local anesthetics and see if the results are consistent.
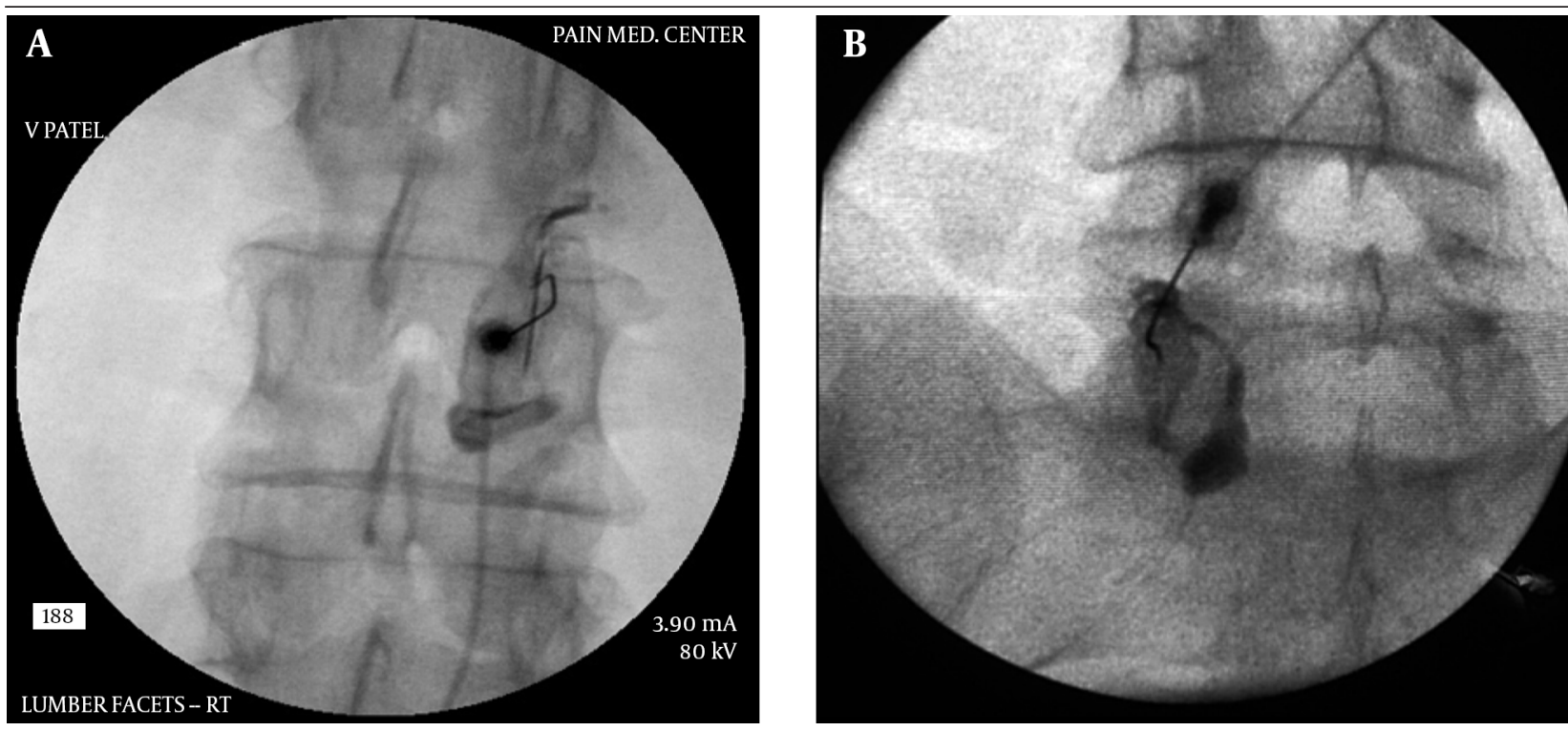

Figure 10. A, B: Lumbar Intra-Articular Facet Joint Injections 


\subsubsection{Technique}

As noted earlier, the lumbar facet joints are innervated by two medial branches for each level hence it is required that both of these medial branches be neurolysed to achieve complete sensory denervation of each joint. The currently practiced method was first described by Shealy $(65,66)$. The needle tip chosen for these procedures is $10 \mathrm{~mm}$ active tip on a $10 \mathrm{~cm}$ radio-frequency needle, usually of $20 \mathrm{G}$ or $22 \mathrm{G}$ size, some practitioners even use an $18 \mathrm{G}$ needle for a bigger lesion. A curved needle is preferable as it can help steer the needle tip to the target with a single pass through the tissue, minimizing tissue trauma as well as provide maximum contact and proximity to the medial branch. To achieve optimal results, the needle is placed tangential to the target point parallel to the nerve to be addressed (rather than perpendicular (67), allowing maximal contact with the nerve (Figure $11 \mathrm{~A}$ - D). This can be achieved by making the skin entry point of the needle at least 1 level below the intended level of the targeted medial branch. The placement of the needle tip is confirmed with fluoroscopic imaging in antero-posterior as well as lateral views. The tip of the needle on lateral view should not encroach upon the neural foramen to avoid any risk of damaging the exiting nerve-root. A sensory stimulation (usually at $\leq 0.5 \mathrm{~V}$ for lower back and negative for lower extremity radiation at $1 \mathrm{~V}$ ) as well as motor stimulation (usually up to $3 \mathrm{~V}$ eliciting multifidus muscle stimulation with absent lower extremity muscle stimulation) is then carried out to confirm the proximity of the needle to the medial branch as well as to rule out any proximity to the exiting nerve-root. However, it should be noted that a sensory stimulation may also be perceived by the patient even if the needle is just within the muscle tissue (50), hence a correlation with fluoroscopy is necessary. After confirmation of proper placement of the needle, injection of local anesthetic + a small amount of steroid is carried out to minimize procedural pain and post-procedural discomfort. The injectate should not have any effect on the lesion generation and may actually help extend the lesion $(68,69)$. A radio-frequency lesion is then carried out for 60 - 90 seconds $(70,71)$ at $60-80^{\circ}$ Celsius. Recent studies have suggested that even placing the needle tip perpendicular to the nerve provides similar results using a larger needle (72).
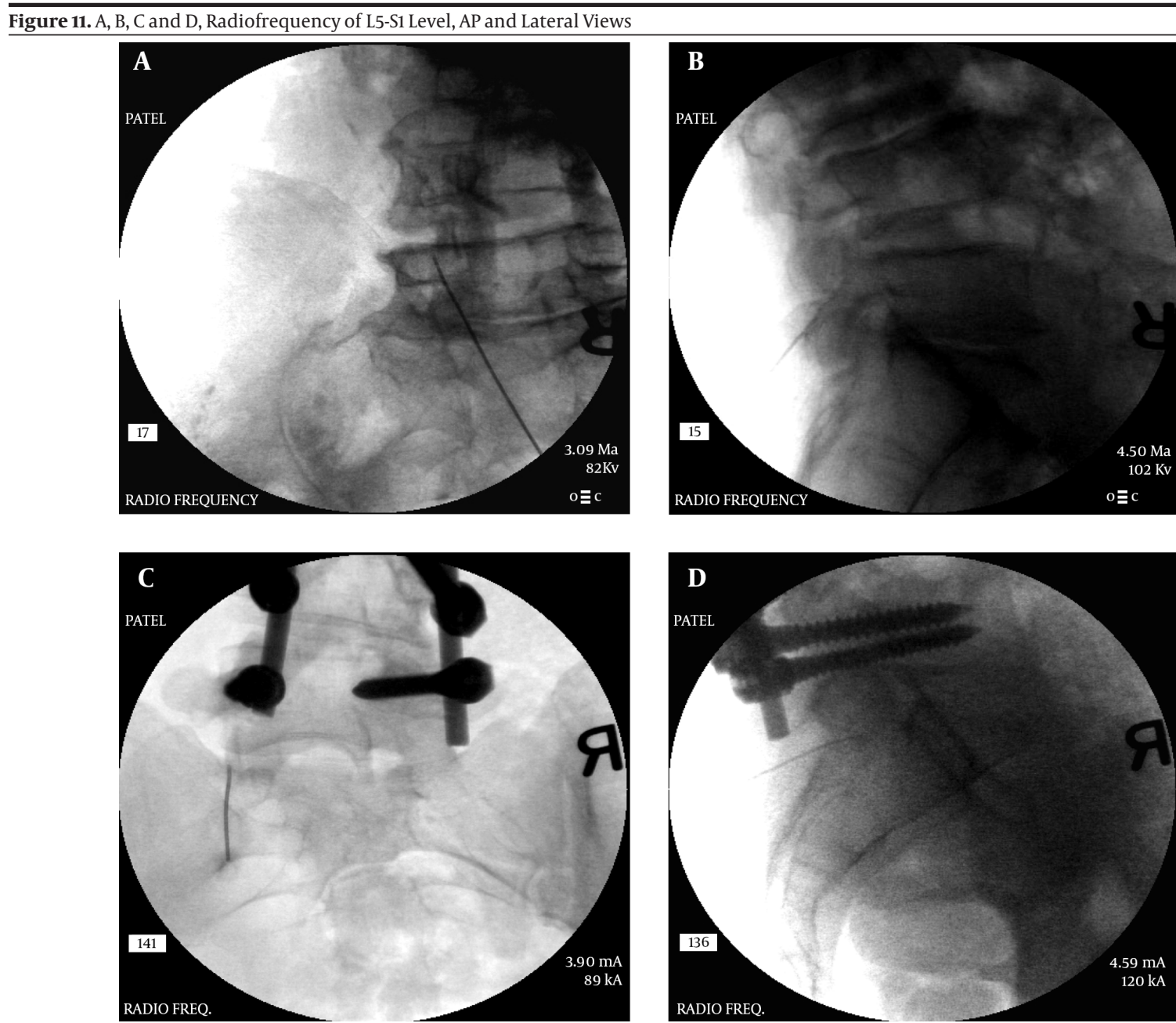

Note the tangential angles of the needles and the L5 medial branch (dorsal ramus) ablation over the ala of the sacrum. 
Patel VB et al.

\subsubsection{Evidence}

Therapeutic effectiveness of radiofrequency ablation of the medial branches for treatment of lumbar facet joint pain has been well studies and established. In the early part of this century, during a double blind placebo controlled trial, Leclaire et al. (73) found that although radiofrequency facet joint denervation may provide some short-term improvement in functional disability among patients with chronic low back pain, the efficacy of this treatment had not been established. Several other studies have shown better outcomes overall. In a prospective randomized double blind trial, van Kleef et al. (74) found that RF for lumbar facet joint denervation results in a significant alleviation of pain and functional disability in a select group of patients with chronic low back pain, both on a short-term and a long-term basis. In a systematic review of the literature, Falco et al. (59) found that there good evidence for the conventional RF for the treatment of Spine chronic lumbar facet joint pain resulting in short-term and long-term pain relief and functional improvement. It efficacy for pain of facet joint origin in spondylolisthesis was also recently studied by Klessinger (75), who found that radiofrequency neurotomy for the facet joint pain is a rational, specific non-operative therapy in addition to other non-operative therapy methods with a success rate of $65 \%$. For post-surgical facet joint pain he found $58.8 \%$ success rate for the lumbar facet joint related pain using radio-frequency neurotomy (76).

\subsection{Sacroiliac Joint Interventions}

Sacroiliac joint is the joint between the lateral aspect of the sacrum and the ilium (Figure 12A and B). It is a true synovial joint but has limited mobility. It differs from other joints in that it has fibro-cartilage as well as hyaline cartilage. It provides stability to the pelvis and has a very irregular articular surface (77). Most of the cephalad portion of this joint is covered posteriorly by the posterior superior iliac spine at the end of the iliac crest. The joint can be accessed in its inferior $1 / 3$ rd to $1 / 5$ th portion under fluoroscopic guidance. The joint has several ligaments around it to help it stabilize. The main ligaments are the long and short sacro-iliac ligaments and sacro-spinous ligament posteriorly and the anterior sacroiliac ligament, sacro-tuberous ligament, Iliolumbar ligament and lumbosacral ligament anteriorly. The sacro-iliac joint is well innervated with nociceptive fibers (77) in its capsule and surrounding ligaments as well as intra-articular area. It has been reported to have nerve supply from ventral rami of L4 and L5, superior gluteal nerve, and the dorsal rami of L5, S1 and S2 $(77,78)$. However, there is also evidence that it is only supplied by the dorsal rami (77).

Figure 12. A and B, Anatomy of the SI Joint (Courtesy Gray's Anatomy Online)
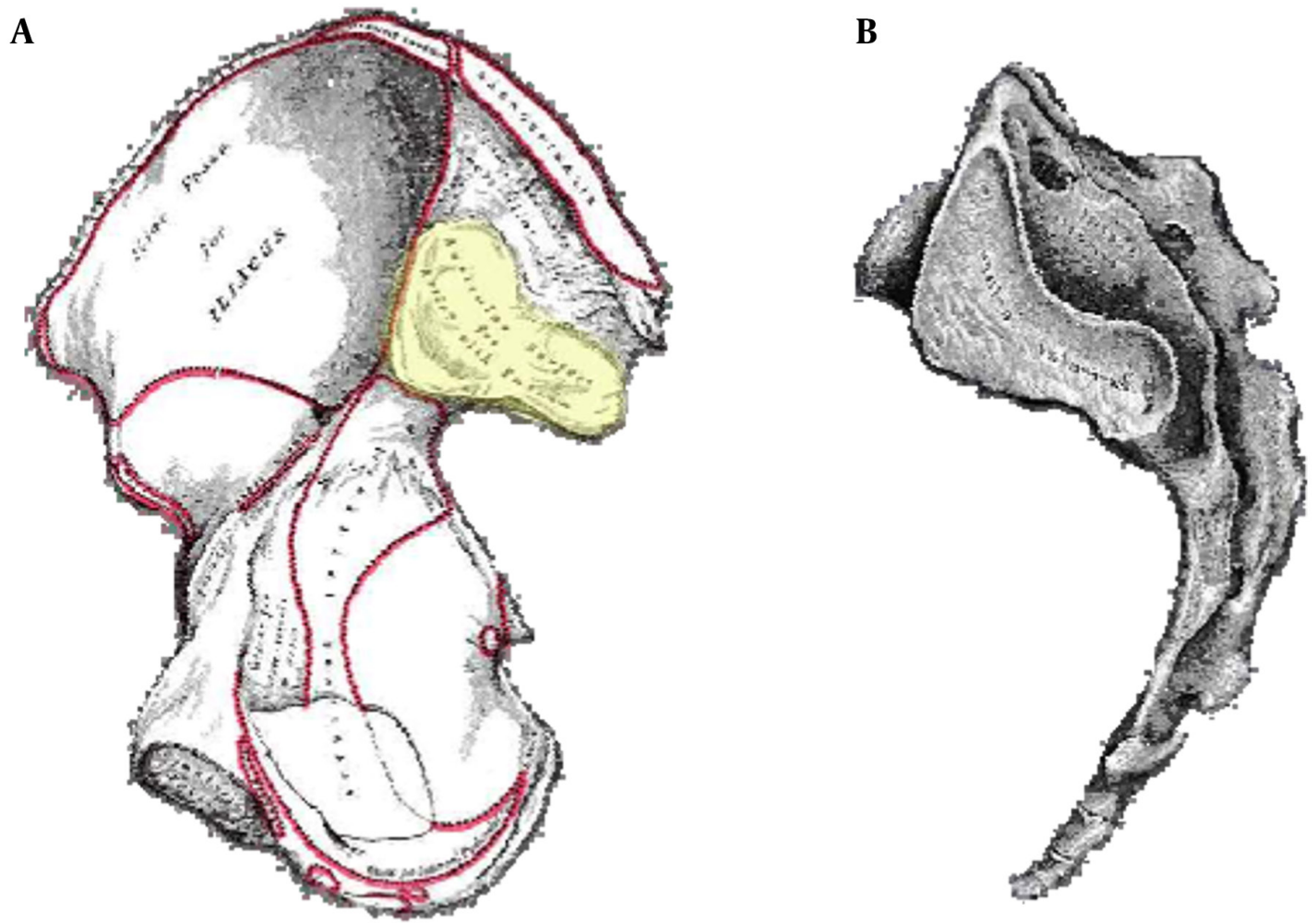

The SI joint articular surface is highlighted in the left image. 
The sacroiliac joint pain is more common in females due to the shape of pelvis as well as ligamentous laxity. It is more common after age of 30 (except due to trauma) and is a significant source of pain if the lumbar fusion is carried to the $\mathrm{S} 1$ segment. The prevalence of sacro-iliac joint pain is $16 \%$ - $30 \%$ of all chronic lower back pain (79). The pain is mainly felt in the gluteal region but may radiate to the groin, abdomen and the lower extremity, usually above the knee (79).

\subsubsection{Intra-Articular Injections of Steroid}

\subsubsection{Technique}

The sacroiliac joint is technically more difficult to access than most other joints. This is because of the anatomical shape of the joint, which has an irregular articular surface unlike most other synovial joints (77) and superimposition of the iliac crest over the joint. "Blind" injections are not recommended as they have a high failure rate (successful in only about $12 \%$ of blind injections) of accessing the joint (4). The best approach to the joint for an intra-articular injection is through the lower $1 / 3$ rd or $1 / 5$ th of the joint. In some individuals the lower $1 / 3$ rd can be seen clearly in a straight antero-posterior view on fluoroscopy but in most patients the fluoroscopic view has to be adjusted to clearly visualize the joint space. A slight tilt from cephalad to caudad direction and a slight oblique rotation towards the contra-lateral side will "open up" the lower joint space. Once the needle is beyond the ligaments and into the joint space, a lateral fluoroscopic view will confirm the depth of the needle and its placement within the joint space.

After confirming the position, a small amount of contrast should be injected and a proper placement will show a linear spread of the contrast within the joint (Figure 13A and B). It should be kept in mind that the soft tissues within the joint may be inflamed and occupying the higher than normal joint space, hence the spread of the contrast may not be ideal and it may start pooling into the inferior cusp of the joint capsule. However, such spread should remain confined within the joint and capsule space and should not show horizontal spread within the ligaments. A small amount of steroid in then injected along with some local anesthetic. The joint can only accommodate about $1.0 \mathrm{~mL}$ of injectate without disrupting the joint capsule (80).

Ultrasound guidance has been recently advocated strongly for the sacroiliac joint injections and can help eliminate the use of fluoroscopy and may also be useful for patients who cannot be subjected to radiation (e.g. pregnant patients)(81-83). The procedure can be time saving and simple in experienced hands.

\subsubsection{Evidence}

Although this is one of the most common procedures performed by pain physicians as well as general practi- tioners, the evidence for intra-articular steroid injection for sacroiliac joint pain is not very strong. In a recent systematic review, Hansen et al. (84) found that the evidence for intra-articular injection of steroids is poor for short as well as long term relief. This could be because of literature deficiency with well controlled randomized studies. However, the diagnostic accuracy for intra-articular injections was found to be good by Simopoulos et al. (85). Overall, the evidence for diagnostic accuracy for sacroiliac joint pain was found to be Level II-2 (86).

Figure 13. A and B: Sacroiliac Joint Intra-Articular Injection Antero-Posterior and Lateral Views

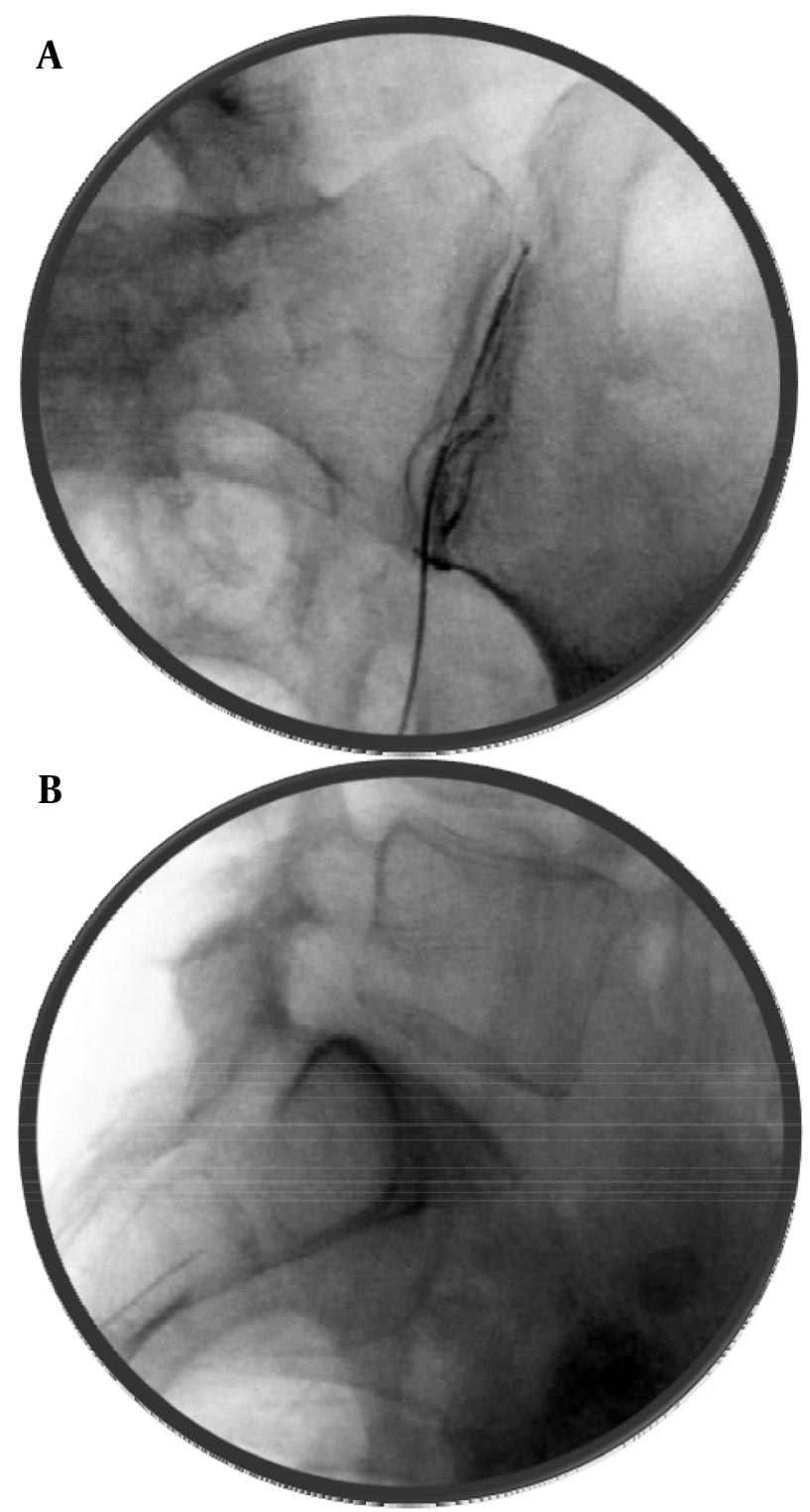

Note the angle of the needle in lateral view, parallel to the joint. 


\subsection{Neuroablative Procedures for the Sacroiliac Joint}

\subsubsection{Cooled Radio-Frequency Ablation (RFA)}

\subsubsection{Technique}

Steroid injection in a degenerated or unstable sacroiliac joint may not provide a long term relief and hence it may be necessary to perform neuroablative procedures. The nerves supplying the joint are not adherent to the bone along their paths and remain 'floating' higher than the bone surface. Conventional radio-frequency procedures do not always succeed in ablating these nerves due to this anatomical fact. Hence the cooled radio-frequency is considered as it can generate a large spherical lesion (Figure 14) from the tip of the needle and can cover the intended nerves. The procedure is time consuming as multiple lesions at the posterior sacral foramina need to be made. The positions of the nerve fibers are variable around the lateral aspect of the foramina. 3 lesions are generated at each level as well as a lesion for the L5 medial branch at the level of the ala of the sacrum.

Under antero-posterior view, a $27 \mathrm{G}$ spinal needle is placed within the posterior sacral foramen to mark the center of the foramen. This may require some optimization of the fluoroscopic view with slight tilt and rotation. After this, the cooled radio-frequency probes are placed at 2, 4, 7 o'clock positions to generate the lesions. This procedure is repeated at S1, S2, S3 and S4 levels to cover the entire nerve supply to the sacro-iliac joint.

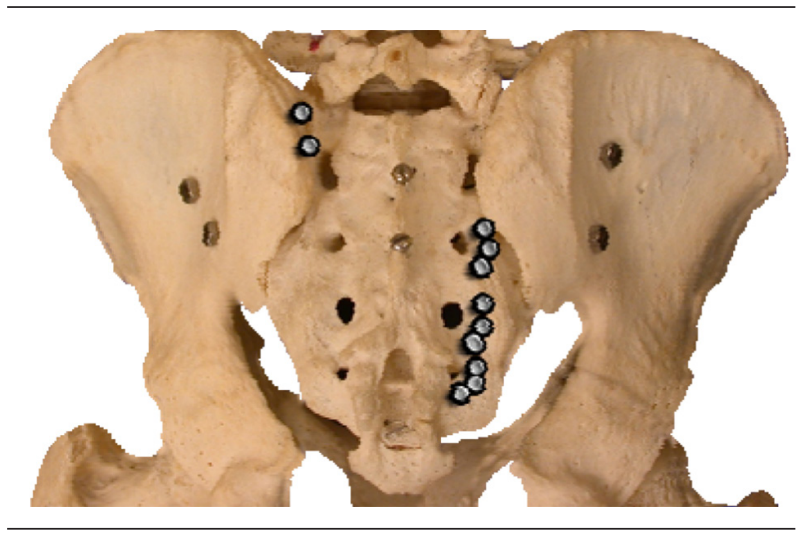

Figure 14. The Image Showing the Spherical Lesions Created by Cooled RF Lesioning and the Targeted Areas Around the Posterior Sacral Foramina as Well as the L5 Lesion Targets

\subsubsection{Evidence}

The steroid injection for sacroiliac joint do not have a strong evidence for reducing pain but they do provide good diagnostic function which should then be followed by a neuroablative procedure. The difficulty in covering the entire complex nerve supply for this joint had led to poor outcomes overall in the past, but the recent advances such as a cooled RF procedure has provided much better outcomes. In a recent systematic review, Hansen et al. (84) found the evidence to be fair overall, which was the best outcome of all the interventions for SI joint. In the first short case study Kapural et al. (87) found that majority of patients with chronic SI joint pain experienced a clinically relevant degree of pain relief and improved function following cooled RF of sacral lateral branches and dorsal ramus of L5 at 3 - 4 months follow-up. Stelzer et al. (88) recently found that cooled RF procedure showed promising, durable improvements in pain, quality of life, and medication usage in a large European study population, with benefits persisting in some subjects at 20 months after treatment. Patel et al. (89) found that in their randomized placebo controlled study, the treatment group showed significant improvements in pain, disability, physical function, and quality of life as compared with the sham group. The duration and magnitude of relief was consistent with previous studies, with benefits extending beyond 9 months.

\subsubsection{Thermal Radio-Frequency Ablation}

\subsubsection{Technique: (Conventional Method)}

Radiofrequency (RF) ablation for the sacroiliac joint is a bit different than for the facet joints. The supplying nerves are not adherent to the bone as is the case with the facet joints. They are relatively floating above the bone within the tissue and have varied locations around the posterior sacral foramina on their way to the joint. Near the joint over the medial border of the joint, they are relatively closer to the bone prior to entering the joint itself. Conventional RF targets this area for ablation. The lesions are created using a bi-polar technique. Two RF needles are placed along the medial border of the joint approximately $5 \mathrm{~mm}$ apart and a lesion is created (Figure 15).

The inferior needle is then moved cephalad to the previously placed needle in a "leap frog" manner for the subsequent lesion (90). A series of such lesions is created along the entire medial border of the joint. The technique requires multiple needle punctures as well as a longer time to finish the procedure.

\subsubsection{Evidence}

RF lesioning for the sacroiliac joint should have the same evidence for efficacy (90) as cooled technique but does not, basically because conventional RF needle positioning may not cover the dorsal branches very effectively due to their anatomical location. Nevertheless, radio-frequency (both pulsed as well as thermal) has been used in treatment of the SI joint pain and has been found to be effective. The bipolar technique described above is thought to be technically simpler and provides adequate pain control for at least short term (91). Vallejo et al. (92) found that pulsed RF denervation of the lateral branch of the medial branch of L4, posterior primary rami of L5, and lateral branches S1 and S2 is an effective treatment for some patients with SIJ pain unresponsive to other forms of therapy with $>70 \%$ patients reporting good to excellent pain relief ranging from 6 to 32 weeks. 

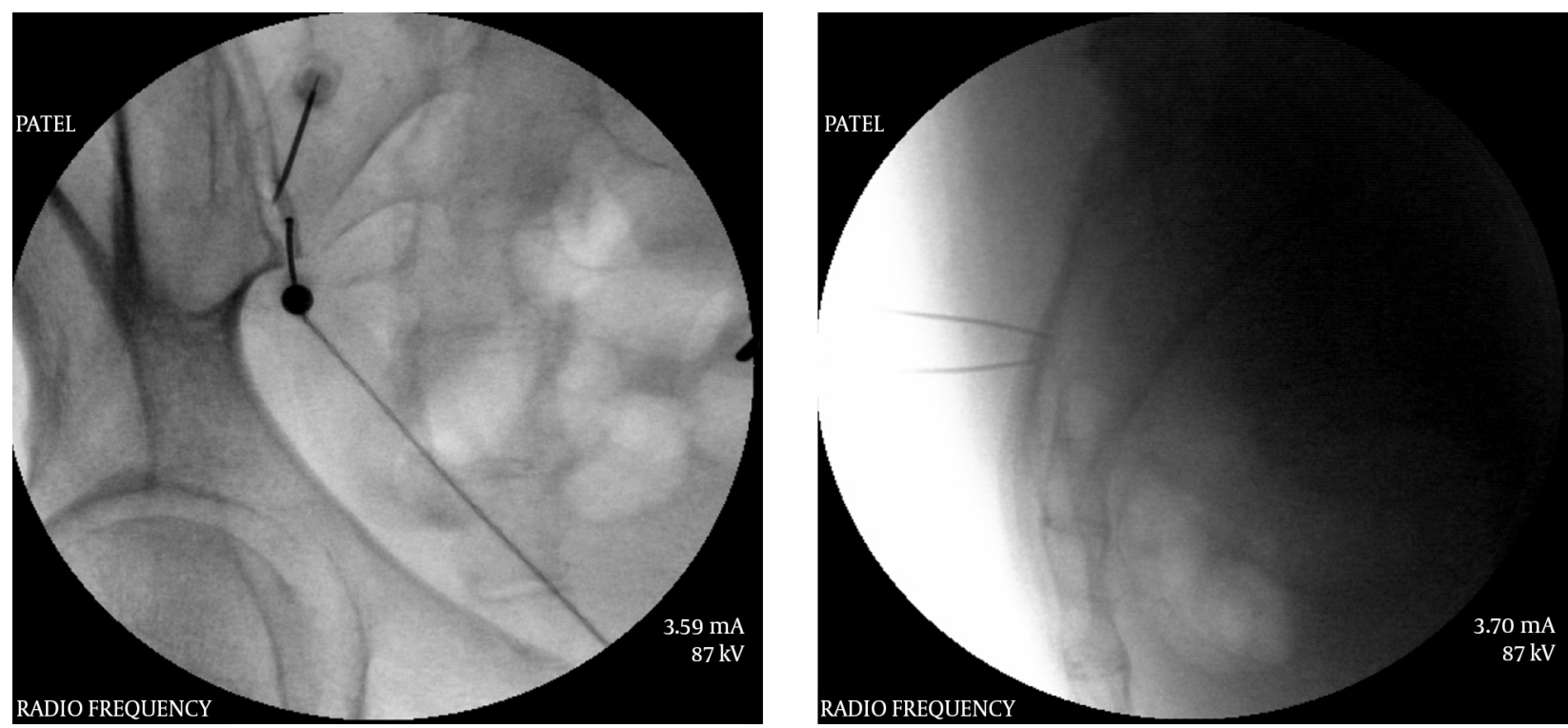

Figure 15. Antero-Posterior and Lateral Views of the RF Lesioning for the SI Joint at the Edge of the Medial Joint Border of the Joint Using the "Leap Frog" Technique

\subsubsection{Technique: (Simplicity III $囚)$}

This procedure utilizes a probe with multiple contacts for RF (Figure 16). The probe itself is curved to match the sacral curvature and is inserted in the cephalad direction with a slightly lateral angulation following the natural curve of the sacrum and the tip is advanced up to the upper aspect of the sacrum. Once in place, the lesions are generated with a single push of a button and multiple needle insertions are not required.

\subsubsection{Evidence}

Not much literature has been published for this procedure. In a recent poster presentation by Mehta et al. (93), all their patients in the study had a reduction in their pain scores at one, two and six months post-procedure compared to baseline. No complications were reported during this period and in their opinion, SIJ RF denervation with the Simplicity III system is a safe and effective treatment modality for SIJ pain.

\subsection{Advanced Interventions for Low Back Pain}

\subsubsection{Procedures for the Intervertebral Disc}

\subsubsection{Diagnostic Discography}

The lumbar intervertebral disc can be a source of significant pain in human beings. The pain is usually related to the annular tears and extrusion of the nuclear material towards the outer $1 / 3$ rd of the disc (94). The damaged disc shows neuropeptide $\mathrm{Y}$ and substance $\mathrm{P}$ only up to the depth of 0.5 to $0.9 \mathrm{~mm}$ in the annulus and except for this area, a normal disc is without any innervations $(95,96)$. As the name suggests, this procedure is purely diagnostic (97) and has little or no prognostic value (98). The test is also thought to be of low specificity (99). Even with a positive test, there are numerous other variables that determine the outcome of a surgical procedure and hence it should only be considered for diagnostic purposes. The results may also be influenced by the subject's emotional and psychological profile (100). The procedure remains controversial due to these facts. However, it can add to the diagnostic value for identifying a patient's pain generator where no apparent source can be located on radiological studies (101). The best diagnostic value is obtained by combining various studies along with the patient's history and physical examination (102).

A post-discogram computerized tomography scan provides a better understanding of the disc damage and whether the nuclear material is extruded of contained and also any disruption of the annulus causing leakage of the injected contrast outside the disc (103). The possible contrast distribution and its correlation has been classified (Dallas Classification) providing a basis for quantifying the disc damage in terms of annular disruption (104). 


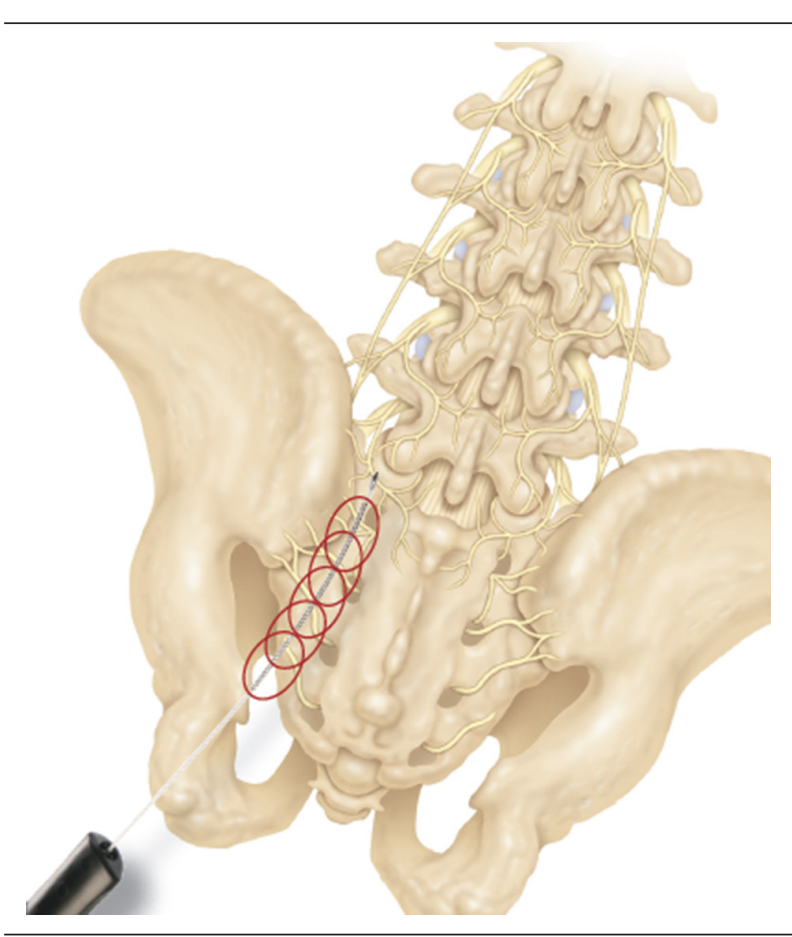

Figure 16. Simplicity® Probe for SI Joint RF Lesioning (Courtesy Neurotherm)

Figure 17. Entry Point for the Discogram With Optimized View for the L4-5 Disc

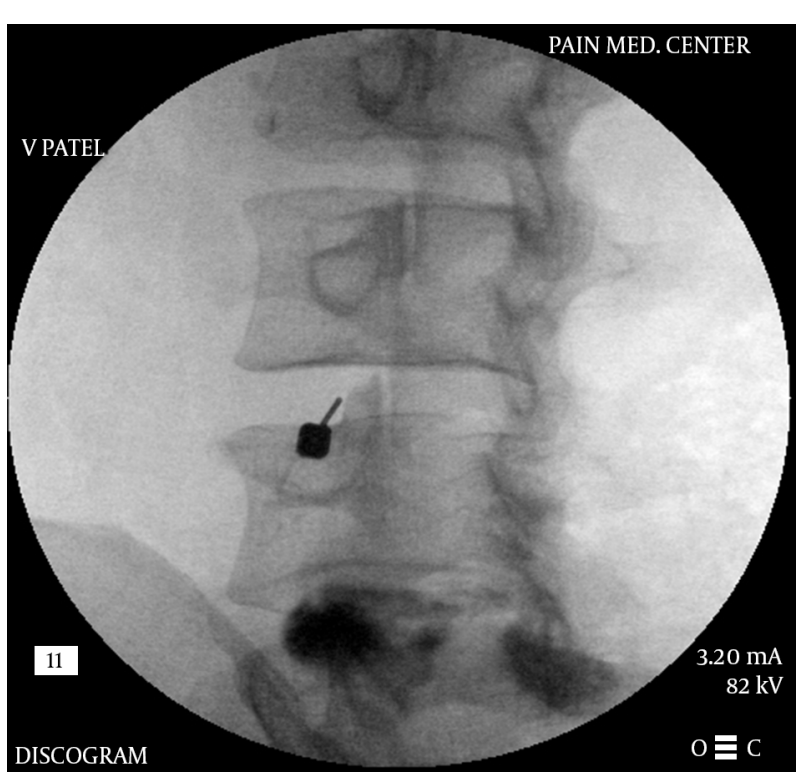

The articular elements of the inferior level bisect the end-plate of the level above in an ideal view.

\subsection{Technique}

The basic concept is to place a needle within the nucleus of the intervertebral disc and inject the contrast material in a controlled graduated manner and pressurize the disc to simulate the normal pain producing situations in a given patient such as sitting, leaning forward etc. which increase the intra-discal pressure $(105,106)$. The pressures are measured at the tip of the needle (107) to reflect the inherent pressure within the disc (opening pressure), pressure when pain is felt (pain pressure), maximum pressure generated (maximum pressure) and the amount of pain felt (usually a numeric rating pain scale) by the patient as well as the total amount of contrast injected (108). Along with the intensity of pain, the concordance of pain is also considered as an important parameter. A painful disc that generates concordant pain is considered to be the main pain generator for the patient's back pain. Occasionally patient may also feel radicular symptoms as the disc may bulge out due to internal pressure and irritate the exiting nerve root. Excessive pressure generation during a discogram can lead to disc disruption in a previously un-ruptured disc and even compression of the intra-spinal structures and should be avoided $(109,110)$.

The safest route to the center of the disc is from the postero-lateral approach under the nerve root. With this angle, the needle can avoid touching the exiting nerve root and thus avoid any pain that might interfere with the interpretation of the test.

The procedure can be performed under CT guidance as well as fluoroscopy (more common). The intended disc is "squared" off so that the X-rays pass parallel to the disc and the superior as well as inferior end-plates do not have parallax. The cephalo-caudad angulation differs depending on the level of the targeted disc. Usually at L3-4 level the disc is almost squared off in an antero-posterior view, whereas at lower levels it requires progressively more cephalo-caudad angulation and the upper levels a slightly more caudo-cephalad angulation. After appropriate angulation based on the target disc level, the c-arm is turned oblique so that the articular elements are approximately bisecting the end-plate above. The entry point for the needle is marked just anterior to the superior articular process (SAP) of the inferior vertebral body (Figure 17).

The choice of needles is sometimes based on the physician's training. A single needle technique is used by many where a $22 \mathrm{G}$ spinal needle is inserted using the above approach up to the middle of the disc within the nucleus. A dual needle technique uses a $20 \mathrm{G}$ introducer needle up to the outer rim of the annulus and a curved discography $25 \mathrm{G}$ needle through it (Figure 18). This technique may help reduce contamination and may help reduce any chance of infection within the disc (Discitis), although it is very rare. Although there are no good studies proving that a double needle technique is safer, it may be because a very low incidence of discitis. Regardless, it is prudent to maintain proper asepsis throughout the procedure. The technique utilized by 
this author uses a double needle technique, Duraprep® prep, Ioban $₫$ drape and a complete body drape. Additionally the performer is fully scrubbed, gowned and gloved similar to a surgical procedure. The patient receives IV antibiotics as well as antibiotic within the injected contrast material. The author's method is to mix up $1 \mathrm{gm}$ of cephazolin in $10 \mathrm{~mL}$ PFNS. Use $9 \mathrm{~mL}$ of this mixture IV and the $1 \mathrm{~mL}$ is then further mixed with $19 \mathrm{~mL}$ of contrast to make $20 \mathrm{~mL}$ of injectate which will then contain $5 \mathrm{mg}$ cephazolin per $\mathrm{mL}$. The dual needle sets are $20 \mathrm{G} 3.5$ or 5 inch introducer needle, $25 \mathrm{G} 6$ or 8 inch discography needle (Figure 18). The longer needles are necessary for the L5-S1 disc in most patients. The introducer needle is inserted in the manner described above and the discography needle (curved) is then introduced through the introducer to reach the center of the disc. The curved needle helps maneuver the needle tip to its desired location without multiple attempts. Especially at the L5-S1 level, when an optimal oblique angle cannot be achieved (due to the iliac crest obstructing the entry) a curved needle can help with proper central placement of the needle tip. Once in position, a manometric syringe with the injectate is attached to the needle. Some newer syringes have a digital manometer attached to them. A controlled injection of the contrast is then carried out measuring the pressures during injection (Figure 19 A and B). Most discography syringes have a graduated injection rate and can inject a very small amount with each turn of the plunger. This helps reduce excessive pressure generation and uncontrolled amount of injection material. A pressure graph can be printed out with some syringes. Pressures such as opening pressure (pressure at which the contrast is first seen entering the disc), pain pressure (pressure at which patient complains of any type of pain), maximum pressure are recorded (Figure $20 \mathrm{~A}$ and $\mathrm{B}$ ). The severity of pain as well as the concordant nature of pain is noted. A post-discogram CT scan can help identify any extra-discal spread of the contrast and helps identify the condition of the annulus of the disc and show if the disc is internally herniated (Figure 21A and B). Further treatment options are based on these findings.

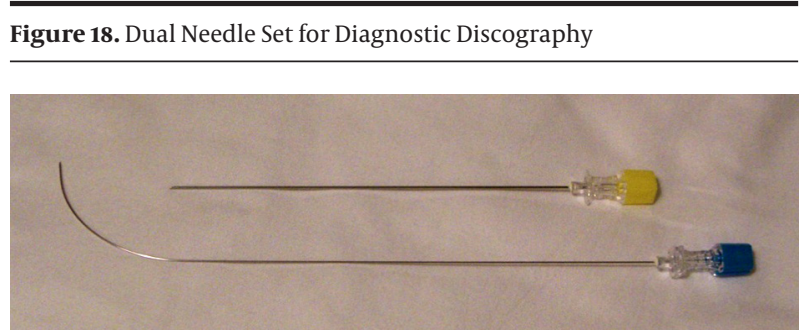

Note the curved inner needle. This curve helps negotiate the needle within the nucleus so that the tip is positioned centrally within the disc. The curvature is reduced significantly as the needle exits the introducer
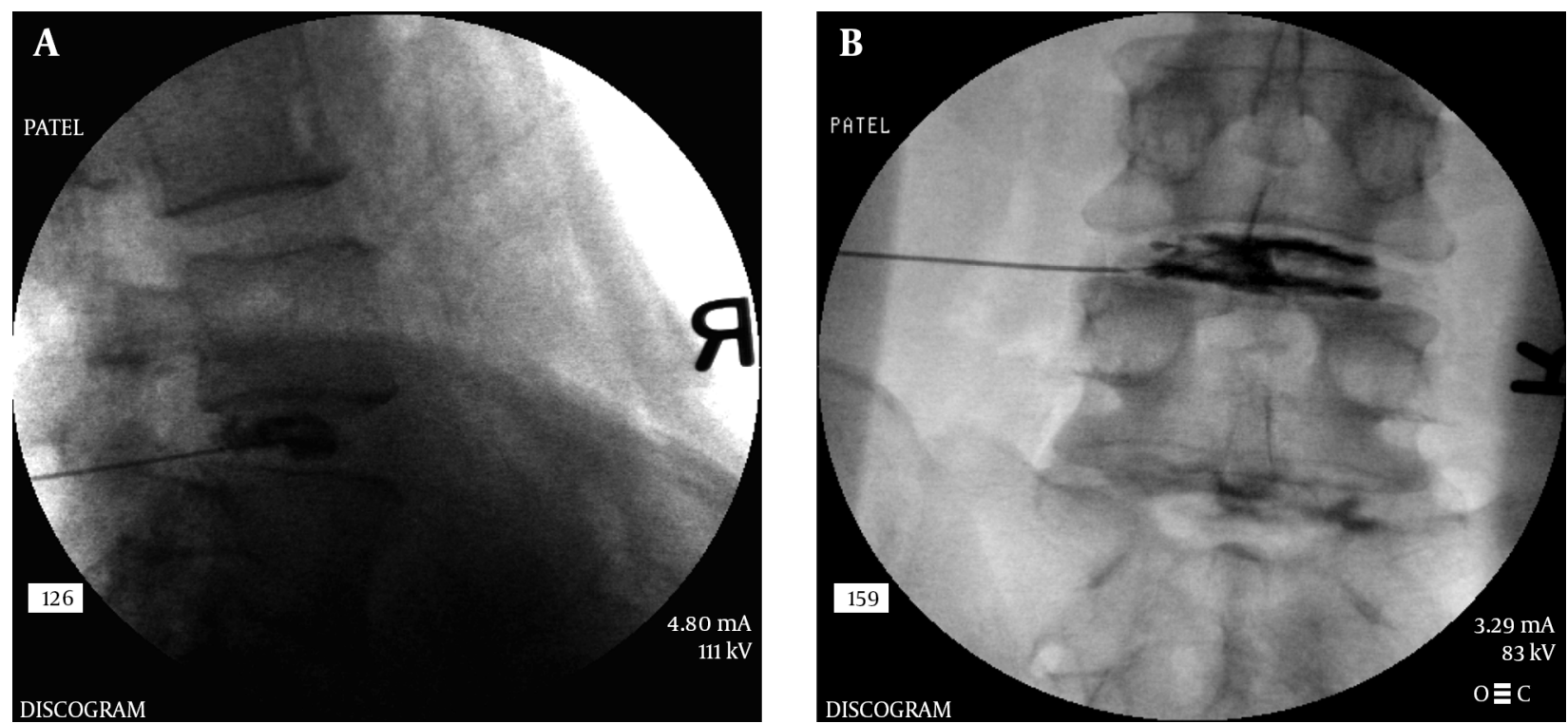

Note that even though the introducer needle is inferior to the center of the disc, the inner needle can achieve a central location of the tip due to the curvature, thus eliminating the need for re-introduction of the needle. 
Patel VB et al.

Figure 20. A and B, Printed Data From a Discography Procedure Showing Graphical as Well as Numeric Readings

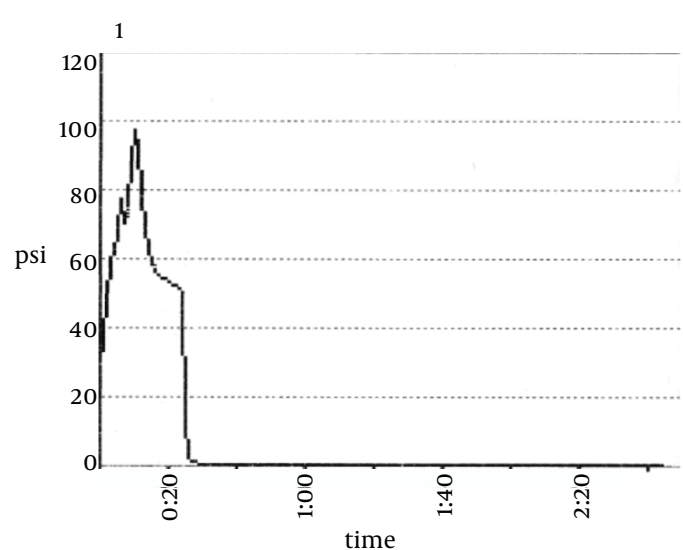

\begin{tabular}{|c|c|c|c|c|}
\hline Pts & $\begin{array}{c}\text { Time } \\
(\mathrm{m}: \mathrm{s})\end{array}$ & $\begin{array}{c}\text { TTL Press } \\
\mathrm{psi}\end{array}$ & $\begin{array}{c}\text { Diff Press } \\
\mathrm{psi}\end{array}$ & $\begin{array}{c}\text { Volume } \\
\mathrm{mL}\end{array}$ \\
\hline 1 & $00: 00$ & 28 & 28 & 00.25 \\
\hline 2 & $00: 11$ & 95 & 95 & 02.00 \\
\hline- & - & - & - & - \\
\hline- & - & - & - & 02.00 \\
\hline P max & $00: 11$ & 101 & 101 & 02.00 \\
\hline V max & $00: 10$ & 88 & 88 & \\
\hline
\end{tabular}

The leads are confirmed to be in the posterior epidural space with a lateral view.

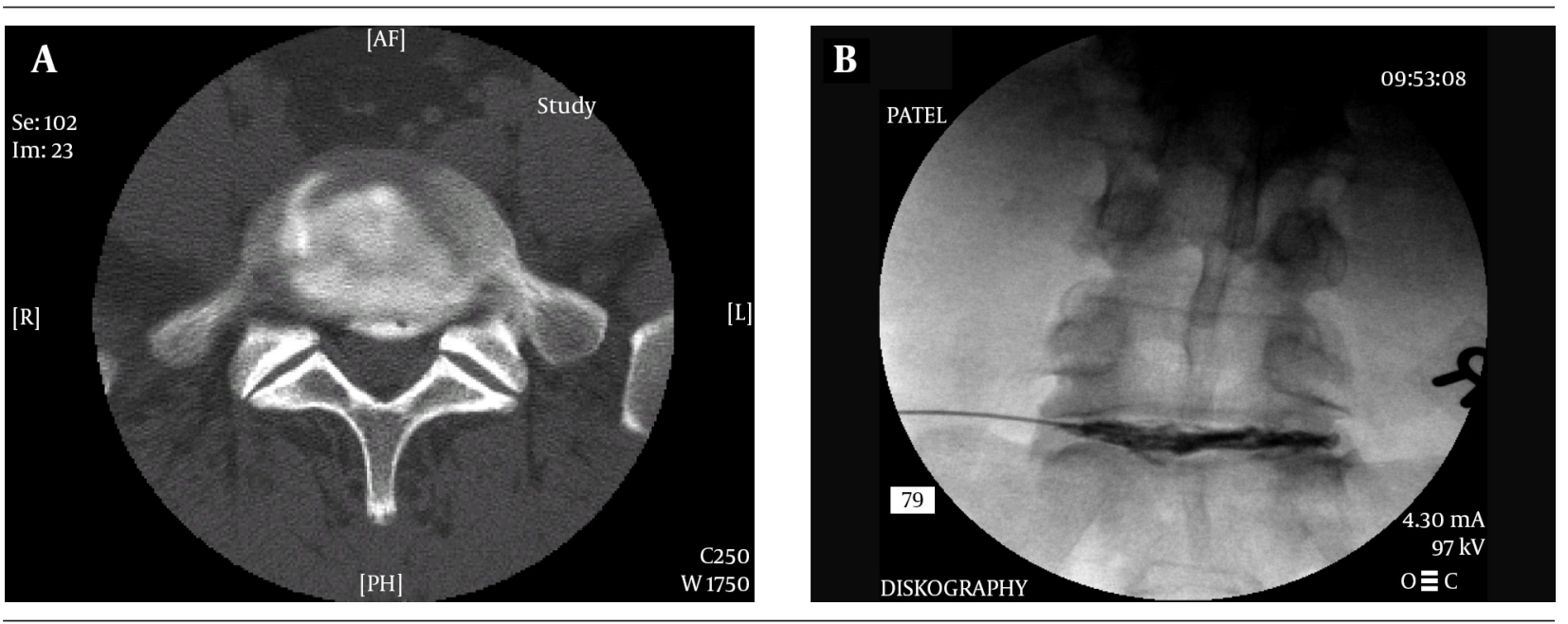

Figure 21. A and B, Post Discogram CT Scan Image Showing Annular Disruption

Figure 22. A and B, Intradiscal Electrothermal Treatment (IDET)

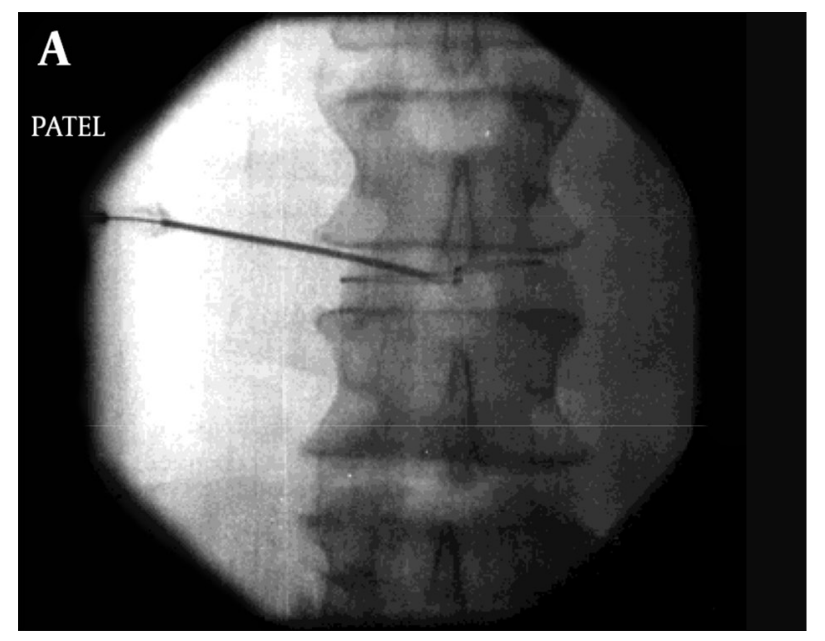

B

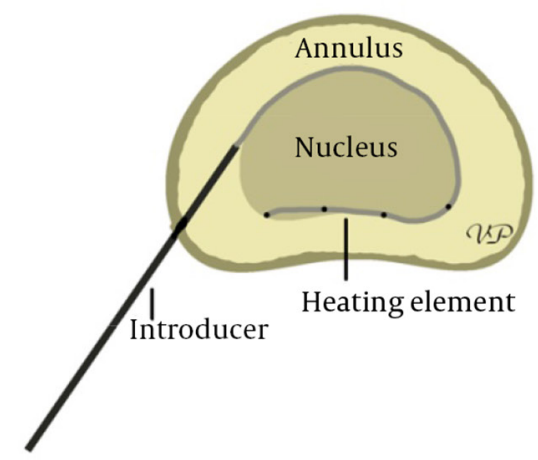

Compare to the fluoroscopic image on the right taken during the procedure. 
Patel VB et al.

\subsection{Evidence}

The diagnostic utility of a properly performed provocation discogram with manometric measurements is well established. However, it should be noted once again that a discogram is not intended for prognostic purposes and cannot predict the results of a procedure including surgery. There is a positive correlation between a history of low back pain and a high intensity zone on an MRI and a higher rate of positive discography (111). Derby et al. (112) had found that patients with chronic low back pain had a significantly lower pain tolerance than asymptomatic subjects during a pressure-controlled manometric discography. They concluded that pressure-controlled manometric discography using strict criteria may distinguish asymptomatic discs among morphologically abnormal discs with Grade 3 annular tears in patients with suspected chronic discogenic LBP. In a systematic review, Manchikanti et al. (113) found that based on controlled evaluations, the lumbar intervertebral discs have been shown to be sources of chronic back pain without disc herniation in $26 \%$ to $39 \%$. The review indicated the strength of evidence as Level II-2 for the diagnostic accuracy of lumbar provocation discography utilizing international association for the study of pain (IASP) criteria.

\subsection{Therapeutic Interventions}

\subsubsection{Disc Decompression}

Several methods for decompressing a painful intervertebral disc are available to an interventional pain physician. It is prudent to try one of these percutaneous methods prior to a surgical option in an attempt to avoid surgery and possible post-surgical complications (114-116). The evidence suggests that surgically treated patients with herniated discs have a similar outcome after 10 years post-surgery. However, about $25 \%$ of patients undergo at least one more repeat surgery which was about the same for non-surgically treated patients requiring first time surgery (117). Same study also found that improvement in the patient's predominant symptom and work and disability outcomes were similar regardless of treatment received. The controversy regarding an open vs. percutaneous disc decompression continues and there is "considerable evidence that surgical discectomy provides effective clinical relief for carefully selected patients with sciatica due to lumbar disc prolapse that fails to resolve with conservative management" (118). Nevertheless, a contained disc herniation is a pain generator with minimal surgical options other than a percutaneous decompression and steroid injections.

A disc that generates concordant pain during a properly performed manometric, provocation discogram and also shows that the herniation is contained and not extruded can be de-compressed by percutaneously removing part of the nucleus. This helps reduce the pressure within the disc and hence irritation of the outer third of the annulus which contains the pain fibers. The procedure itself uses almost the same approach to the disc as a discogram. Various methods are available to remove part of the nucleus, thereby reducing the pressure within the disc so that the bulge is reduced. This can help alleviate the pressure upon a nerve root and help with radicular pain and/or help prevent progression of the nuclear material to the outer level of the annulus, helping with discogenic lower back pain. Several methods for decompressing a disc with internal contained herniation (as evidenced with a properly conducted diagnostic discogram and a postdiscogram CT scan) have been studied. At least 4 different methods are available and have been utilized extensively. These include a DeKompressor@, a coblation wand, laser assisted decompression and automated percutaneous device for decompression.

\subsubsection{Technique}

The technique for decompression is essentially the same with various modalities. Usually a large bore trocar is introduced within the disc and advanced up to its center through a postero-lateral approach percutaneously. The access is similar to performing a discogram. The fluoroscopic image is optimized per level and the cephalad-caudad angulation may vary with each level with highest angulation at the L5-S1 level. The higher levels at L2-3 and above require an opposite angulation with a more caudad-cephalad tilt. The obliquity of the fluoroscopy also varies according the level and should be rotated such that the articular elements of the lower level nearly bisect the vertebral end-plate of the upper level on the image. With this optimized image the entry point is similar to the discography entry point at the anterior border of the superior articular process of the inferior vertebral body. Once the introducer trocar is in place at the center of the disc the actual decompressing element is then introduced under fluoroscopic view and decompression carried out. In case of the DeKompressor@, a high speed rotating element which is a battery operated self-contained unit, is introduced and multiple passes are made under live fluoroscopy. A live image is advisable to avoid penetrating the anterior annulus and thus entering the vital abdominal structures. The procedure extracts small amount of the nuclear material which can be visualized and sent for pathological study to ascertain its nature. Usually the unit is operated for about 1 minute and the material examined for its volume. A small amount of nuclear material is extracted which is sufficient to reduce the intra-discal pressure and can help with discogenic pain. Nucleoplasty using the coblation technique is a similar procedure with nearly identical technique. However, it requires bigger equipment which then provides radio-frequency energy to ablate and then coagulate the material. The ablation phase literally vaporizes the tissue with heat at 400 - 700 centigrade by breaking 
the bonds between the molecules. This gaseous material then escapes through the cannula. The bulk of the nucleus is thus reduced and the intradiscal pressure is decreased. Multiple passes are made by rotating the coblation wand under live fluoroscopic view.

\subsubsection{Evidence}

In a systematic review of literature, Singh et al. (119) concluded that one of the commonly used disc extraction unit (DeKompressor $®$ ) provided only a level III evidence for efficacy using United States Preventive Services Task Force (USPSTF) criteria. In another review, Manchikanti et al. (120) studied another device for nucleoplasty and considering pain relief as the primary outcome measure, found that there was a level II-3 evidence for mechanical lumbar percutaneous disc decompression with nucleoplasty in the treatment of leg pain. However, there was no high quality evidence available in managing axial low back pain. Lierz et al. (121) showed in a relatively small group of patients that there was a significant reduction of pain overall from 7.3 to 2.1 after a year. A reduction of analgesic use was also observed after disc decompression using a DeKompressor® wand.

With Coblation® nucleoplasty, Singh et al. (122) found that overall, $75 \%$ of patients indicated a decrease in their numeric pain scores at 12 months with a statistically significant reduction in numeric pain scores. The results indicated that disc decompression using Coblation $®$ (Nucleoplasty) was a safe and efficacious procedure for reducing discogenic low back pain with or without leg pain. A long term evaluation of this procedure was carried out by Zhu et al. (123). In a 2 year study, they found that nucleoplasty may have satisfactory clinical outcomes for treatment of protruded lumbar intervertebral disc for as long as two-year follow-up with significant improvement in their VAS scores.

LASER has also been used to treat the disc with minimally invasive technique. During a systematic review of literature, Singh et al. (124) noted that the level of evidence for percutaneous lumbar laser discectomy (PLLD) is II-2 for short- and long-term relief which was found to be equivalent to automated percutaneous lumbar disc decompression. In a more recent study, Zhao et al. (125) concluded that target percutaneous laser disc decompression (T-PLDD) can significantly decrease pain and improve function of patients who have extruded but non-sequestered lumbar intervertebral disc herniation.

\subsubsection{Thermal Annular Procedures}

The thermal procedures for the annular disruptions have evolved within the past two decades. This technique has been used extensively by interventional pain physicians to treat a disrupted annulus of the disc. In the past, attempts were made to use radiofrequency ablation for the outer annulus to treat discogenic low back pain caused due to annular disruption with poor outcomes. This was thought to be due to lack of moisture within the disc which is necessary for radiofrequency to generate heat. To overcome this problem, a flexible heating element was devised to be introduced within the disc and guided to the posterior annulus at the nuclear-annular junction through a small cannula. This was the first type of device that was used and is called IDET® (IntraDiscal Electrothermal Therapy) (Figure $22 \mathrm{~A}$ and $\mathrm{B}$ ). IDET ${ }^{\circledR}$ is thought to decrease discogenic pain by 2 different mechanisms: thermal modification of collagen fibers and destruction of disc nociceptors. Disctrode $®$ is a similar device that provides heating element to achieve similar results. Cooled radiofrequency has also been used to treat annular disruptions. It is claimed that such a lesion is larger and also avoids heating up the intra-spinal tissue and thus help minimize the risk of damaging the exiting nerve root during the procedure.

\subsubsection{Technique}

Technique varies according to the procedure. However, the standard approach to the disc remains largely unchanged. The use of IDET® requires passing a flexible heating element through the introducer cannula (Figure 22A and B) and placing it between the nucleus and the annulus in the posterior part of the disc. The passage of the heating element requires proper angle of the cannula in the disc and a certain finesse to avoid breaking it. Once in place, the equipment delivers electrical energy to heat up the element and raise the intradiscal temperature to $900 \mathrm{C}$. In a recent cadaveric study the temperatures generated by IDET have been found to be safe for the intra-spinal structures and did not appear to be high enough to cause any nerve damage (126).

Procedure for cooled radio-frequency procedure requires placement of dual introducers through bilateral postero-lateral approaches. The tips of the main RF elements are positioned at the nuclear-annular junction (Figure 23A and B) where the equipment delivers radiofrequency through a water cooled probe on each side.

\subsubsection{Evidence}

In one of the earlier studies, Saal (127) showed that patients with low back pain of discogenic origin whose symptoms had failed to improve with aggressive non-operative care demonstrated a statistically significant and clinically meaningful improvement on the short form health survey (SF-36) and the visual analog scale (VAS) scores at a minimum follow-up of 1 
year after IDET. However, Freeman et al. (128), in a randomized, double-blind placebo controlled trial found that although the IDET procedure appeared safe with no permanent complications, no subject in either arm met criteria for successful outcome. Further detailed analyses showed no significant change in outcome measures in either group at 6 months. This study demonstrated no significant benefit from IDET over placebo. Pauza et al. (129) published the results of a randomized placebo controlled trial for discogenic low back pain showing that patients in both groups (treated and sham) exhibited improvements, but mean improvements in pain, disability and depression were significantly greater in the group treated with IDET. More patients deteriorated when subjected to sham treatment, whereas a greater proportion showed improvements in pain when treated with IDET. They concluded that IDET appeared to provide worthwhile relief in a small proportion of strictly defined patients. Similar method was used with Disctrode @ which also uses a thermal element to coagulate the outer annulus. In a randomized double-blind controlled trial for this procedure, Kvarstein et al. (130) found that a 6-month analysis did not reveal any trend towards overall effect or difference between active and sham treatment for the primary endpoint: change in pain intensity $(0-10)$, after 12 months the overall reduction from baseline pain had reached statistical significance, but there was no significant difference between the groups, hence they would not recommend intra-annular thermal therapy with the discTRODE $®$ probe.

Cooled radiofrequency had been studied initially at the Cleveland Clinic. Kapural and Mekhail (131) published an initial report of a patient showing that biacuplasty procedure showed significant improvement in patient functional capacity, and pain scores also improved after 6 months. Later in a follow up study (132), he concluded that patients showed improvements in several pain assessment measures after undergoing IDB (intradiscal Biacuplasty®) for discogenic pain. More recently in a randomized, placebo controlled trial for IDB (133), after 6 months, patients in the IDB group exhibited statistically significant improvements in physical function, pain, and disability compared to the sham group. It was concluded that IDB should be recommended to select the patients with chronic discogenic low back pain. In a comparative study of cooled versus traditional radiofrequency ablation of the lateral branches for sacroiliac joint pain, Cheng et al. (134) did not find any significant univeriable relationship between radiofrequency techniques and the duration of pain relief and concluded that cooled radiofrequency does not provide longer relief from the sacroiliac joint pain. This study demonstrates that a larger lesion produced by cooled radiofrequency is not superior to a properly conducted conventional lesion. However, the precision required in the placement of a conventional needle may not be that critical with cooled radiofrequency due to a larger lesion being generated.

Recently, Helm et al. (135) did a systematic review of literature to study the thermal annular procedures (TAP) and found that the evidence is fair for IDET $®$ and poor for DiscTRODE®. They did not comment on Biacuplasty® as the studies were not published yet.

Figure 23. A and B, Biacuplasty® Procedure With Cooled Radiofrequency

A
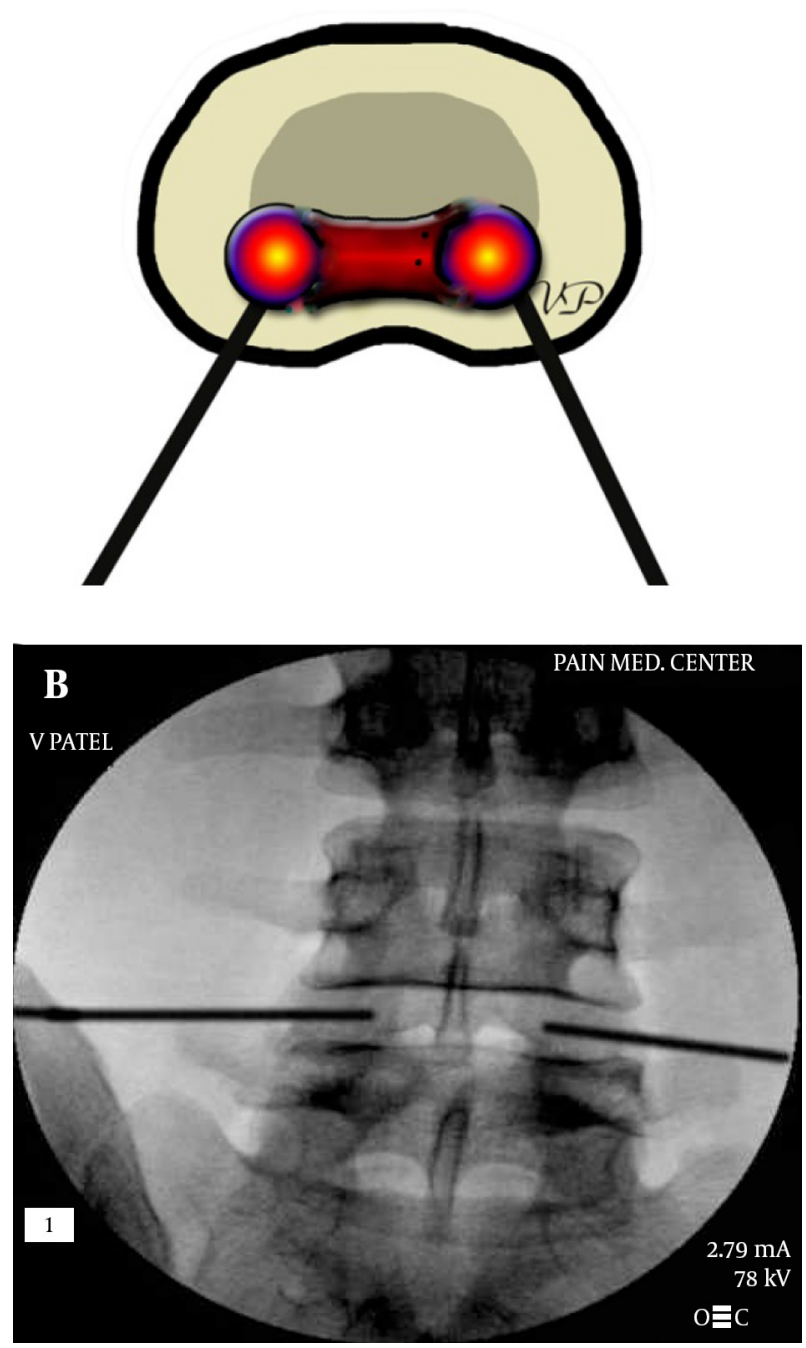

The entry point is at the posterolateral annulus and the thermal element is guided through the introducer at the annular-nuclear junction with the final position in the posterior aspect of the disc. 
Figure 24. A, B, C and D: Spinal Cord stimulator Lead Placement for Low Back Pain as Well as Radicular Pain in a Post-Laminectomy Pain Patient Using a Dual Lead Configuration
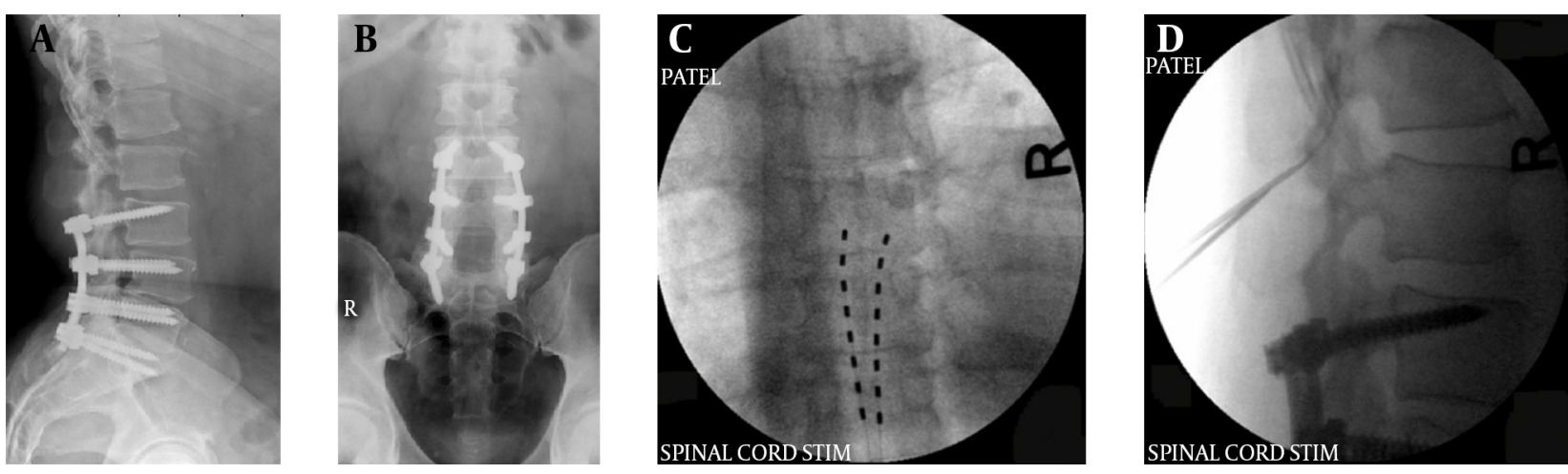

The lesion is generated between the tips of the probes and provides a near complete coverage of the posterior annulus.

\subsubsection{Intrathecal Infusion Devices}

Intrathecal infusions have been used for pain for decades. This modality was mainly offered to cancer pain patients in the past, but since the mid-1990s it has gained widespread utilization for non-cancer pain as well. The procedure involves placement of a catheter within the dural sac providing precisely measured doses of medications directly into the spinal fluid. The device itself is implanted in a sub-cutaneous pocket, usually created in the anterior abdominal wall. There are computerized pumps of varied capacities available for implant which can be programmed precisely to deliver various amounts of the injectate. Various other pumps are also available that are capable of delivering a fixed amount of injectate but cannot be programmed. These pumps operate mechanically and commonly utilize a refrigerant under pressure. To change the dosage, one has to alter the concentration of the drug being delivered. The efficacy of opiates delivered in this manner provides not only a significant reduction in the amount of medication required for adequate analgesia, but also helps reduce the incidence of side effects due to systemic effects of opiates. United States food and drug administration (FDA) has currently approved only morphine sulphate, ziconotide (the only non-opiate drug approved for chronic pain) and baclofen (for centrally originating spasticity) for such use in these devices for pain and floxuridine and methotrexate for treatment of cancer (136). Although not approved by FDA, several medications have been successfully used for infusion. These include fentanyl, sufentanil and local anesthetics such as bupivacaine.

\subsubsection{Technique}

The delivery method for intra-thecal infusions ranges from simple external infusion pumps connected to the Intrathecal catheters placed percutaneously to highly sophisticated computerized, programmable pumps that are implanted sub-cutaneously. The technique for placement of an implantable intrathecal infusion devise is relatively simple but requires surgical skills. Procedure can be performed under spinal or general anesthesia. The access to the intra-thecal space is achieved using a large bore needle placed percutaneously at the mid-lumbar region. A flexible styleted catheter is then passed through this needle and guided under fluoroscopic view to the thoraco-lumbar junction region. Once the catheter is in place, it is tunneled sub-cutaneously from the midline in the back to the front in the lower abdominal area using a tunneling device. A sub-cutaneous pocket is then surgically created in the anterior abdominal wall and the infusion devise is placed within this pocket and optionally secured. The catheter is also surgically secured to the inter-spinous ligament to prevent migration. External infusion devices are preferred for a relatively short term use and for terminally ill patients.

\subsubsection{Evidence}

Long term effect of this modality has been associated with significant complications. Intrathecal granuloma formation at the tip of the catheter has been known to cause spinal cord compression. Although studies showing the incidence are not in abundance, several case reports have been published in the recent past (137-141). In a systematic review that we conducted in 2009 (142) we found that despite the high costs of chronic non-cancer pain, it had been claimed that there was lack of evidence for intrathecal infusion systems for the use in chronic non-cancer pain and the cost effectiveness of these systems had been questioned in improving pain and function. The level of evidence for intrathecal infusion systems indicated either Level II-3 or Level III (limited) for non-cancer pain. We also noted that limitations of that study included paucity of literature, lack of quality evidence, and lack of randomized trials. Earlier in 2004 Deer et al. (143) published "Intrathecal drug delivery for treat- 
Patel VB et al.

ment of chronic low back pain: report from the National Outcomes Registry for Low Back Pain". They had found that at 12-month follow-ups, implanted patients experienced reductions in numeric back and leg pain ratings, improved Oswestry scores, and high satisfaction with the therapy. Smaller patient groups have been studied for various low back pain diagnoses. Lara et al. (144) studied 30 patients with failed back surgery syndrome and found that intrathecal infusion of morphine is a useful and safe tool for long-term treatment of chronic nonmalignant pain. Anderson and Burchiel (145) prospectively studied 40 patients with chronic non-cancer pain and concluded that continuous intrathecal morphine can be safe and effective therapy for severe non-malignant pain among carefully selected patient population and can result in improvement of long term areas of daily function. In another small study, Kumar et al. (146) concluded that in their experience, the administration of intrathecal opioid medications for nonmalignant pain is justified in carefully selected patients. The common conclusion in these and several other studies is that the patient selection has to be carefully made in order to obtain a successful outcome.

Newer drugs approved for use in implanted pumps may provide better outcomes. Ziconotide is one such drug that has been well studied. Rauck et al. (147) found that Ziconotide is a potential therapeutic option for chronic refractory neuropathic pain. Lynch et al. (148) concluded that Ziconotide is a therapeutic option for treatment of severe chronic pain in patients who have exhausted all other agents, including intrathecal morphine, and for whom the potential benefit outweighs the risks of serious neuropsychiatric adverse effects and of having an implanted device. In a clinical update, Pope and Deer (149) suggested that Concomitant use of Ziconotide and morphine is an option when considering use of FDA-labeled intrathecal drugs in those resistant to monotherapy.

\subsubsection{Spinal Cord Stimulation (SCS)}

Spinal cord stimulation solely for lower back pain is an indication not yet approved by FDA. However, several articles have been published that show its efficacy. Most patients with failed back surgery syndrome have a combination of low back pain as well as radicular leg pain. Majority of the studies have been done on patients with lower back as well as leg pain and thus a quality study is lacking for lower back pain alone. Nevertheless, SCS has been extensively used alone or in combination with other interventions including intrathecal infusion devices to achieve satisfactory pain relief in a patient with chronic pain. This modality has been shown to be more effective and less costly in the long term compared to the other interventions or conservative management of a patient with chronic low back pain $(150,151)$. However, careful patient selection is necessary for optimal outcomes and it may not be cost effective in certain patient populations such as workers' compensation patients (152) and the ini- tial high procedural cost may not be offset by lower cost of subsequent care.

\subsubsection{Technique}

The described technique for coverage of low back pain is similar to the lead placements for post laminectomy syndrome with radicular pain. Usually two leads are placed (153) but several practitioners have been using more than two leads. Additionally multi contact surgical leads are also available. These leads are paddle shaped and have multiple arrays of contacts providing better coverage and deeper penetration of the applied current.

The permanent and sometimes temporary lead placement procedure is performed with strict aseptic precautions similar to a surgery in an operating room. Some practitioners place the temporary lead in clean rather than sterile rooms. The percutaneous method involves placing an introducer needle in the upper lumbar epidural space usually at L1-2 level (Figure 24A - D). The needle needs to be angulated cephalad to facilitate the passage of the lead smoothly into the epidural space. Loss of resistance technique is utilized to identify the entry of the needle into the epidural space. The stimulator lead(s) is then introduced and guided in the posterior epidural space under fluoroscopic guidance and advanced in the paramedian area up to the T8-T9 level under very light sedation and local anesthesia at the entry point. At this point the patient is confirmed to be wide awake and responsive to commands. The lead is then connected to a temporary external stimulator and the pattern of stimulation established to cover the affected painful area. A second (and sometimes a third) lead is also placed in a similar manner. For the trial stimulation, these leads are then secured to the skin at the entry point and patient is allowed to go home with the stimulator connected externally. Usually the trial period may vary between physicians from 3 to 10 days. It is thought that a shorter trial period may reduce therapeutic failures, risk of infection as well as the cost of therapy (154). The temporary leads are removed after the trial period and the patient may receive a permanent implant if the trial was effective in relieving the pain.

The permanent placement of leads is similar to the trial placement. After the leads are satisfactorily positioned and tested for the stimulation pattern, they are tunneled through the subcutaneous area to the implantable pulse generator (IPG) placed in a subcutaneous pocket created below or above the beltline posteriorly in most cases. The lead(s) is then secured to the interspinous ligament using an anchor device. Recent advances in the design of these anchoring devices have simplified the anchoring process and may provide a more secure method as compared to the past methods. Most of the modern IPGs are rechargeable and are relatively small in diameter and thin requiring only a small subcutaneous pocket. Various systems have various options for programming the 
system. An external programmer/controller can program the implanted IPG remotely. It is said that covering the lower back for pain is relatively more difficult and hence multiple leads and contacts are necessary. Surgically placed leads require a laminotomy performed under general anesthesia and hence the patient response to the initial stimulation is not possible. A minimally invasive laminotomy for paddle lead placement has been studied under spinal anesthesia as well and that method may be preferable as the patient can be awake and responsive during the testing phase as the stimulation is carried out at a level higher than the block (155). However, a percutaneous trial followed by a surgical placement may provide better stability during the initial period when lead migration is more common. Newer systems are available for percutaneous as well as surgical placements and tend to overcome several of these difficulties in covering lower back with a stimulator. One of the newest systems can place an array of stimulator leads, or a narrow paddle lead percutaneously. In a recent article Deer et al. (156) described this method of placement of a paddle lead via a minimally invasive percutaneous method, as well as complex cylindrical arrays with a single needle entry to the epidural space. The device functioned successfully and presented a safe option for placing paddle leads and complex arrays. It's safe use has been corroborated by Loge et al. (157) in a series of 34 patients. The method is safe and effective as well as has a low migration rate (158).

\subsubsection{Evidence}

In a review article, Epstein and Palmieri (159) found that there is strong evidence for efficacy and cost effectiveness of spinal cord stimulation in the treatment of pain associated with intractable angina, failed back surgery syndrome, and complex regional pain syndrome. Clinical studies revealed a success rate of from $50 \%$ to $70 \%$ with spinal cord stimulation, with decreased pain intensity scores, functional improvement and decreased medication usage. In a relatively small study of $41 \mathrm{pa}-$ tients with predominantly lower back pain, Ohnmeiss and Rashbaum (160) noted that majority of patients were satisfied with the results of SCS and would have the procedure again knowing what their outcome would be. In a prospective multicenter study, Burchiel et al. (161) found that Spinal cord stimulation can be an effective therapy for management of chronic low back and extremity pain. They included more than 200 patients with lower back and leg pain. All the pain and quality-of-life measures showed statistically significant improvement during the treatment year using VAS, McGill Pain Questionnaire, Oswestry Disability Questionnaire, Sickness Impact Profile, and the Back Depression Inventory. Another study published recently in this journal, looking also at a combination of lower back and leg pain (162) showed that a hybrid, surgically placed lead in failed back surgery patients, is capable of alleviating both low back and leg pain. Stimulator placement is a costly procedure and the initial argument was against such treatment but it has been found to be more cost effective than conventional medical management (CMM) of chronic pain in several studies. Taylor and Taylor (163) noted that in selected patients with FBSS, SCS is cost effective both as an adjunct to CMM and as an alternative to reoperation. Bala et al. (150) performed a systematic review of cost effectiveness of SCS in FBSS patients. They found that SCS is both more effective and less costly in the treatment of FBSS in terms of pain reduction in the long-term. Compared to repeat spinal surgery, spinal cord stimulation is more effective in the treatment of persistent radicular pain and it obviates the need for re-operation (164). This study did not address low back pain issues in these patients, but considering the fact that most failed back surgery patients also have back pain along with radicular symptoms, it may be an effective choice for improving their life style and productivity. North et al. (165) also studied the efficacy of spinal cord stimulation compared to other interventional modalities and found that SCS had a statistically significant advantage over reoperation after 6 months. A systematic review published by Frey et al. (166), although not just for lower back pain but post-laminectomy syndrome as a whole, showed the evidence to be Level II-1 or II-2 for clinical use on a long-term basis for relieving chronic intractable pain.

\subsubsection{Peripheral Nerve Field Stimulation (PNFS) for Low Back Pain}

Peripheral nerve field stimulation is a relatively newer modality utilizing the neuromodulation technique. While spinal cord stimulation alone often may be able to provide coverage for axial low back pain at the time of placement, constant adjustments to the programming is required over time period to achieve adequate coverage for pain (167). Including peripheral nerve field stimulation along with spinal cord stimulation provides a better outcome for control of chronic pain which is axial in nature.

\subsubsection{Technique}

Technique for placement of leads for peripheral nerve field stimulation is simpler than a spinal cord stimulator placement. Peripheral nerve field stimulation for low back pain has been most commonly studied for failed back surgery syndrome (FBSS) pain and involves placement of multiple stimulator leads within the sub-cutaneous space in the lumbo-sacral region. The leads surround the painful aspect of the lower back and are commonly used in conjunction with centrally placed SCS leads. With no clear guidelines for appropriate depth for placement of these leads, it is difficult to achieve reproducible results. Observing that a shallower placement may be too painful and lack efficacy and a placement too deep may 
Patel VB et al.

be uncomfortable including muscle contractions, Abejon et al. (168) used radiofrequency stimulation probe to identify the appropriate depth of the leads to help achieve proper depth of placement.

\subsubsection{Evidence}

In one of the larger and early prospective observational studies, Verrills et al. (169) found that in 100 consecutive patients receiving peripheral nerve field stimulation (PNFS) for the treatment of chronic intractable pain, an overall $72 \%$ of patients reduced their analgesic use following PNFS and showed a significant reduction in their disability determined by the Oswestry Disability Index. Bernstein et al. (170) studied a group of 20 patients with chronic low back and leg pain syndromes who had failed conventional therapies. These patients underwent implantation of a combination of traditional SCS (epidurally) and PNFS (around the field of maximum intensity of lumbar pain) if the trial stimulation showed more than $50 \%$ of improvement in their pain. Majority of patients found the combination better in controlling their overall pain rather than either modality alone. Another small but prospective study by Mironer et al. (171) studied two groups of 20 patients each. In the first part 20 patients were implanted with SCS and PNFS. They selected the best program out of three: SCS alone, PNFS alone, or both together. In the second part another 20 patients with the same implanted leads were selecting between three programs: SCS and PNFS separately, SCS as anode and PNFS as cathode, or in reverse. They concluded that communication between SCS and PNFS provided wider coverage of axial pain and simultaneous use of SCS and PNFS increased the efficacy of both methods for axial back pain. More recently, in a small study, Reverberi et al.(172) placed octapolar as well as quadrapolar leads for spinal cord as well as peripheral nerve field stimulation and found that when used in conjunction with spinal cord stimulation, PFNS provided a significant reduction in opiate intake as well as reduction in the disability and pain after one year. Yakovlev et al. (173) showed that in a small group of patients with post-laminectomy syndrome (PLS) suffering from low back pain, four vertically orientated leads provide an effective treatment option for patients with PLS after multilevel surgical procedures with intractable low back pain who had failed conservative treatment after 12 months follow up. In a retrospective study, Burgher et al. (174) studied sub-cutaneous lead placements on patients with axial low back pain and found that was a promising therapy for axial neck and back pain based on a small cohort of patients. They used ultrasound to assist with electrode placement at the most appropriate depth beneath the skin. While inter-lead stimulation had been preferred by patients in published reports, they did not find it clearly influenced pain relief.

Although these studies show a significant advantage of using sub-cutaneously placed leads for PFNS along with
SCS for axial low back pain, a larger prospective randomized study is still lacking.

\subsubsection{High Frequency Stimulation for Low Back Pain}

Conventional spinal cord stimulation can be more effective in decreasing low back pain if a higher frequency of stimulation is utilized. The placement of the leads and the rest of the procedure remains essentially the same, except the difference in programming. Such high frequencies do not produce paresthesiae. The frequency can be achieved up to $10 \mathrm{kHz}$ with the use of certain SCS systems. It is shown in an animal study that delivery of high frequency current $(3-50 \mathrm{kHz}$ ) to the region of epidural nerve root or nerve root entry inhibits afferent nociceptive input and therefore may be an alternative to traditional spinal cord stimulation without sensory paresthesiae as neuronal activation cannot occur at frequencies in this range (175).

\subsubsection{Technique}

Technique for the placement of these leads is the same as a conventional SCS.

\subsubsection{Evidence}

Recent literature has shown significant success with this method for SCS. Van Buyten et al (176) studied eighty three patients with back pain and treated them with a dual eight-contact leads placed percutaneously. Patients' pain ratings, disability, sleep disturbances, and satisfaction were assessed for up to six months. Seventy-four percent of patients had greater than $50 \%$ back pain relief at six months. There were significant improvements in Oswestry disability score and sleep, and reductions in pain medication use. This was achieved without the sensation of paresthesiae and results confirmed a favorable safety and efficacy profile of the high-frequency SCS system. In a smaller study, Tiede et al. (177) found that patients with predominant back pain reported a substantial reduction in overall pain and back pain when trialed with highfrequency spinal cord stimulation therapy. To confirm these findings, Perruchoud et al. (178) compared the effects of high frequency stimulation to a sham group in a double blind study with patients who were already stable on conventional spinal cord stimulation therapy. They noted that the mean benefit of high frequency vs. sham was not statistically significant and it appeared that the effect of HFSCS and sham is equal and only the order in the sequence, not the nature of the treatment, seems to dictate the effect.

Another newer and emerging technology in this field is dorsal root ganglion stimulation. Proper long term studies are yet to be seen in the published literature although several are ongoing at this time. The future for neurostimulation is much more promising than ever due to newer technology and advances in electronic technol- 
ogy. Use of an accelerometer has also been emerging to regulate the amount of stimulation based on a patient's position.

\section{Conclusions}

Low back pain is a major health problem in the civilized nations. One of the reasons may be the prevalence of inactivity in this population. Disorders of the lumbar spine are among the most common medical problems in western countries, affecting up to $80 \%$ of people at some time during their lives (179). Although initially managed by oral analgesics, low back pain can get severe enough to require light to heavy opiate medications. Opiates for lower back pain do not have much convincing evidence and compared to interventional therapies, they have fewer efficacies not only in controlling pain but also improving function. Several modalities for controlling lower back pain in specific conditions are available to a pain practitioner. Not only do they help reduce or even eliminate the use of systemic analgesics, but also improve functional capacities as evidenced in abundance of published literature. Proper diagnosis is definitely the first step towards providing proper treatment options. Several modalities may be required in most of the patients. Various treatment options, when combined, provide the best outcomes such as combining physical therapy, psychological modalities, and medications along with interventional procedures.

\section{References}

1. Williams KA, Gonzalez-Fernandez M, Hamzehzadeh S, Wilkinson I, Erdek MA, Plunkett A, et al. A multi-center analysis evaluating factors associated with spinal cord stimulation outcome in chronic pain patients. Pain Med. 2011;12(8):1142-53.

2. van Dulmen S, Sluijs E, van Dijk L, de Ridder D, Heerdink R, Bensing J. Patient adherence to medical treatment: a review of reviews. BMC Health Serv Res. 2007;7:55.

3. Manchikanti L, Cash KA, Pampati V, McManus CD, Damron KS Evaluation of fluoroscopically guided caudal epidural injections. Pain Physician. 2004;7(1):81-92.

4. Hansen HC. Is fluoroscopy necessary for sacroiliac joint injections? Pain Physician. 2003;6(2):155-8.

5. Jasper JF. Role of digital subtraction fluoroscopic imaging in detecting intravascular injections. Pain Physician. 2003;6(3):369-72.

6. Jasper JF. Is digital subtraction flouroscopy a useful tool for the interventional pain physician? Pain Physician. 2002;5(1):36-9.

7. Gandini R, Chiocchi M, Maresca L, Pipitone V, Messina M, Simonetti G. Chronic contained rupture of an abdominal aortic aneurysm: from diagnosis to endovascular resolution. Cardiovasc Intervent Radiol. 2008;31 Suppl 2:S62-6.

8. Hasegawa K, Katsuta E, Iwata N, Aoyagi H, Yoshida T, Takahata $\mathrm{T}$, et al. [A case of locally advanced pancreas cancer effectively treated by multidisciplinary strategy]. Gan To Kagaku Ryoho. 2011;38(12):2152-4.

9. Patel SN, Kettner NW. Abdominal aortic aneurysm presenting as back pain to a chiropractic clinic: a case report.J Manipulative Physiol Ther. 2006;29(5):409 e1-7.

10. Lavelle ED, Lavelle W, Smith HS. Myofascial trigger points. Med Clin North Am. 2007;91(2):229-39.

11. Alvarez DJ, Rockwell PG. Trigger points: diagnosis and management. Am Fam Physician. 2002;65(4):653-60.

12. Soares A, Andriolo RB, Atallah AN, da Silva EM. Botulinum toxin for myofascial pain syndromes in adults. Cochrane Database Syst Rev. 2012;4:CD007533.

13. Jabbari B. Treatment of chronic low back pain with botulinum neurotoxins. Curr Pain Headache Rep. 2007;11(5):352-8.

14. Manchikanti KN, Pampati V, Damron KS, McManus CD. A doubleblind, controlled evaluation of the value of sarapin in neura blockade. Pain Physician. 2004;7(1):59-62.

15. Cotchett MP, Landorf KB, Munteanu SE. Effectiveness of dry needling and injections of myofascial trigger points associated with plantar heel pain: a systematic review. J Foot Ankle Res. 2010;3:18.

16. Ay S, Evcik D, Tur BS. Comparison of injection methods in myofascial pain syndrome: a randomized controlled trial. Clin Rheumatol. 2010;29(1):19-23.

17. Mathis JM. Epidural steroid injections. Neuroimaging Clin N Am 2010;20(2):193-202.

18. Manchikanti L, Cash KA, McManus CD, Pampati V, Benyamin R. Fluoroscopic lumbar interlaminar epidural injections in managing chronic lumbar axial or discogenic pain. J Pain Res 2012;5:301-11.

19. Cannon DT, Aprill CN. Lumbosacral epidural steroid injections Arch Phys Med Rehabil. 2000;81(3 Suppl 1):S87-98.

20. Manchikanti L, Cash KA, McManus CD, Pampati V. Fluoroscopic caudal epidural injections in managing chronic axial low back pain without disc herniation, radiculitis, or facet joint pain. $J$ Pain Res. 2012;5:381-90.

21. Kranz PG, Raduazo P, Gray L, Kilani RK, Hoang JK. CT fluoroscopy-guided cervical interlaminar steroid injections: safety, technique, and radiation dose parameters. AJNR Am J Neuroradiol. 2012;33(7):1221-4.

22. Kim H, Lee SH, Kim MH. Multislice CT fluoroscopy-assisted cervical transforaminal injection of steroids: technical note. J Spina Disord Tech. 2007;20(6):456-61.

23. Manchikanti L, Malla Y, Wargo BW, Cash KA, Pampati V, Fellows B. A prospective evaluation of complications of 10,000 fluoroscopically directed epidural injections. Pain Physician. 2012;15(2):131-40.

24. Manchikanti L, Singh V, Cash KA, Pampati V, Falco FJE. The Role of Fluoroscopic Interlaminar Epidural Injections in Managing Chronic Pain of Lumbar Disc Herniation or Radiculitis: A Randomized, Double-Blind Trial. Pain Pract. 2013;13(7):547-58.

25. Benyamin RM, Manchikanti L, Parr AT, Diwan S, Singh V, Falco FJ, et al. The effectiveness of lumbar interlaminar epidural injections in managing chronic low back and lower extremity pain. Pain Physician. 2012;15(4):E363-404.

26. Stitz MY, Sommer HM. Accuracy of blind versus fluoroscopically guided caudal epidural injection. Spine (Phila Pa 1976). 1999;24(13):1371-6.

27. Sekiguchi M, Yabuki S, Satoh K, Kikuchi S. An anatomic study of the sacral hiatus: a basis for successful caudal epidural block. Clin J Pain. 2004;20(1):51-4

28. Nagar SK. A study of sacral hiatus in dry human sacra.J Anat Soc India. 2004;53(2):18-21.

29. Kumar V, Nayak SR, Potu BK, Pulakunta T. Sacral hiatus in relation to low back pain in south Indian population. Bratisl Lek Listy. 2009;110(7):436-41.

30. Cleary M, Keating C, Poynton AR. The flow patterns of caudal epidural in upper lumbar spinal pathology. Eur Spine $J$. 2011;20(5):804-7.

31. Rabinovitch DL, Peliowski A, Furlan AD. Influence of lumbar epidural injection volume on pain relief for radicular leg pain and or low back pain. Spine J. 2009;9(6):509-17.

32. Botwin KP, Gruber RD, Bouchlas CG, Torres-Ramos FM, Hanna A Rittenberg J, et al. Complications of fluoroscopically guided caudal epidural injections. Am J Phys Med Rehabil. 2001;80(6):416-24.

33. Parr AT, Manchikanti L, Hameed H, Conn A, Manchikanti KN, Benyamin RM, et al. Caudal epidural injections in the management of chronic low back pain: a systematic appraisal of the literature Pain Physician. 2012;15(3):E159-98.

34. Conn A, Buenaventura RM, Datta S, Abdi S, Diwan S. Systematic review of caudal epidural injections in the management of chronic low back pain. Pain Physician. 2009;12(1):109-35.

35. Vad VB, Bhat AL, Lutz GE, Cammisa F. Transforaminal epidural 
Patel VB et al.

steroid injections in lumbosacral radiculopathy: a prospective randomized study. Spine (Phila Pa 1976). 2002;27(1):11-6.

36. Benny B, Azari P. The efficacy of lumbosacral transforaminal epidural steroid injections: a comprehensive literature review. $J$ Back Musculoskelet Rehabil. 2011;24(2):67-76.

37. Schaufele MK, Hatch L, Jones W. Interlaminar versus transforaminal epidural injections for the treatment of symptomatic lumbar intervertebral disc herniations. Pain Physician. 2006;9(4):361-6.

38. Manchikanti L, Cash KA, Pampati V, Damron KS, McManus CD. Evaluation of lumbar transforaminal epidural injections with needle placement and contrast flow patterns: a prospective, descriptive report. Pain Physician. 2004;7(2):217-23.

39. Jasper JF. Lumbar retrodiscal transforaminal injection. Pain Physician. 2007;10(3):501-10.

40. Park KD, Lee JH, Park Y. Injectate Volumes Needed to Reach Specific Landmarks and Contrast Pattern in Kambin's Triangle Approach with Spinal Stenosis. Ann Rehabil Med. 2012;36(4):480-7.

41. Park JW, Nam HS, Cho SK, Jung HJ, Lee BJ, Park Y. Kambin's Triangle Approach of Lumbar Transforaminal Epidural Injection with Spinal Stenosis. Ann Rehabil Med. 2011;35(6):833-43.

42. Choi YK, Barbella JD. Evaluation of epidurographic contrast patterns with fluoroscopic-guided lumbar interlaminar ventral epidural injection. Pain Pract. 2009;9(4):275-81.

43. Levi D. Intradiscal flow during a transforaminal epidural steroid injection. Pain Med. 2010;11(5):716-8.

44. Moon HS, Shin BC, Im HS, Song BH, Cha YD. Inadvertent discogram during transforaminal epidural injection in patients with lumbar disc herniation -A report of 2 cases. Korean J Anesthesiol. 2010;58(1):104-8.

45. Lutz GE, Vad VB, Wisneski RJ. Fluoroscopic transforaminal lumbar epidural steroids: an outcome study. Arch Phys Med Rehabil. 1998;79(11):1362-6.

46. Manchikanti L. Transforaminal lumbar epidural steroid injections. Pain Physician. 2000;3(4):374-98.

47. Boswell MV, Colson JD, Sehgal N, Dunbar EE, Epter R. A systematic review of therapeutic facet joint interventions in chronic spinal pain. Pain Physician. 2007;10(1):229-53.

48. Issack PS, Cunningham ME, Pumberger M, Hughes AP, Cammisa FJ. Degenerative lumbar spinal stenosis: evaluation and management. J Am Acad Orthop Surg. 2012;20(8):527-35.

49. Manchikanti L, Singh V, Cash KA, Pampati V, Datta S. Preliminary results of a randomized, equivalence trial of fluoroscopic caudal epidural injections in managing chronic low back pain: Part 3Post surgery syndrome. Pain Physician. 2008;11(6):817-31.

50. Datta S, Lee M, Falco FJ, Bryce DA, Hayek SM. Systematic assessment of diagnostic accuracy and therapeutic utility of lumbar facet joint interventions. Pain Physician. 2009;12(2):437-60.

51. Cohen SP, Raja SN. Pathogenesis, diagnosis, and treatment of lumbar zygapophysial (facet) joint pain. Anesthesiology. 2007;106(3):591-614.

52. Bogduk N. The innervation of the lumbar spine. Spine (Phila Pa 1976). 1983;8(3):286-93.

53. Stojanovic MP, Zhou Y, Hord ED, Vallejo R, Cohen SP. Single needle approach for multiple medial branch blocks: a new technique. Clin J Pain. 2003;19(2):134-7.

54. Stojanovic MP, Dey D, Hord ED, Zhou Y, Cohen SP. A prospective crossover comparison study of the single-needle and multipleneedle techniques for facet-joint medial branch block. Reg Anesth Pain Med. 2005;30(5):484-90.

55. Greher M, Kirchmair L, Enna B, Kovacs P, Gustorff B, Kapral S, et al. Ultrasound-guided lumbar facet nerve block: accuracy of a new technique confirmed by computed tomography. Anesthesiology. 2004;101(5):1195-200.

56. Dreyfuss P, Schwarzer AC, Lau P, Bogduk N. Specificity of lumbar medial branch and L5 dorsal ramus blocks. A computed tomography study. Spine (Phila Pa 1976). 1997;22(8):895-902.

57. Manchikanti L, Singh V, Pampati V. Are diagnostic lumbar medial branch blocks valid? Results of 2-year follow-up. Pain Physician. 2003;6(2):147-53.

58. Sehgal N, Dunbar EE, Shah RV, Colson J. Systematic review of diagnostic utility of facet (zygapophysial) joint injections in chronic spinal pain: an update. Pain Physician. 2007;10(1):213-28.
59. Falco FJ, Manchikanti L, Datta S, Sehgal N, Geffert S, Onyewu O, et al. An update of the effectiveness of therapeutic lumbar facet joint interventions. Pain Physician. 2012;15(6):E909-53.

60. Dory MA. Arthrography of the lumbar facet joints. Radiology. 1981;140(1):23-7.

61. McCormick CC, Taylor JR, Twomey LT. Facet joint arthrography in lumbar spondylolysis: anatomic basis for spread of contrast medium. Radiology. 1989;171(1):193-6.

62. Schleifer J, Fenzl G, Wolf A, Diehl K. [Treatment of lumbar facet joint syndrome by CT-guided infiltration of the intervertebral joints]. Radiologe. 1994;34(11):666-70.

63. Yun DH, Kim HS, Yoo SD, Kim DH, Chon JM, Choi SH, et al. Efficacy of ultrasonography-guided injections in patients with facet syndrome of the low lumbar spine. Ann Rehabil Med. 2012;36(1):66-71.

64. Civelek E, Cansever T, Kabatas S, Kircelli A, Yilmaz C, Musluman $\mathrm{M}$, et al. Comparison of effectiveness of facet joint injection and radiofrequency denervation in chronic low back pain. Turk Neurosurg. 2012;22(2):200-6.

65. Shealy CN. Percutaneous radiofrequency denervation of spinal facets. Treatment for chronic back pain and sciatica. J Neurosurg. 1975;43(4):448-51.

66. Shealy CN. Facet denervation in the management of back and sciatic pain. Clin Orthop Relat Res. 1976(115):157-64.

67. Lau P, Mercer S, Govind J, Bogduk N. The surgical anatomy of lumbar medial branch neurotomy (facet denervation). Pain Med. 2004;5(3):289-98.

68. Dobrogowski J, Wrzosek A, Wordliczek J. Radiofrequency denervation with or without addition of pentoxifylline or methylprednisolone for chronic lumbar zygapophysial joint pain. Pharmacol Rep. 2005;57(4):475-80.

69. Demazumder D, Mirotznik MS, Schwartzman D. Comparison of irrigated electrode designs for radiofrequency ablation of myocardium.J Interv Card Electrophysiol. 2001;5(4):391-400.

70. Bogduk N, Macintosh J, Marsland A. Technical limitations to the efficacy of radiofrequency neurotomy for spinal pain. Neurosurgery. 1987;20(4):529-35.

71. Buijs EJ, van Wijk RM, Geurts JW, Weeseman RR, Stolker RJ, Groen GG. Radiofrequency lumbar facet denervation: a comparative study of the reproducibility of lesion size after 2 current radiofrequency techniques. Reg Anesth Pain Med. 2004;29(5):400-7.

72. Gofeld M, Faclier G. Radiofrequency denervation of the lumbar zygapophysial joints-targeting the best practice. Pain Med. 2008;9(2):204-11.

73. Leclaire R, Fortin L, Lambert R, Bergeron YM, Rossignol M. Radiofrequency facet joint denervation in the treatment of low back pain: a placebo-controlled clinical trial to assess efficacy. Spine (Phila Pa 1976). 2001;26(13):1411-6.

74. van Kleef M, Barendse GA, Kessels A, Voets HM, Weber WE, de Lange S. Randomized trial of radiofrequency lumbar facet denervation for chronic low back pain. Spine (Phila Pa 1976). 1999;24(18):1937-42.

75. Klessinger S. Radiofrequency neurotomy for treatment of low back pain in patients with minor degenerative spondylolisthesis. Pain Physician. 2012;15(1):E71-8.

76. Klessinger S. Zygapophysial joint pain in post lumbar surgery syndrome. The efficacy of medial branch blocks and radiofrequency neurotomy. Pain Med. 2013;14(3):374-7.

77. Forst SL, Wheeler MT, Fortin JD, Vilensky JA. The sacroiliac joint: anatomy, physiology and clinical significance. Pain Physician. 2006;9(1):61-7.

78. Nakagawa T. [Study on the distribution of nerve filaments over the iliosacral joint and its adjacent regio $\mathrm{n}$ in the Japanese]. $\mathrm{Ni}$ hon Seikeigeka Gakkai Zasshi. 1966;40(4):419-30.

79. Vanelderen P, Szadek K, Cohen SP, De Witte J, Lataster A, Patijn J, et al. 13. Sacroiliac joint pain. Pain Pract. 2010;10(5):470-8.

80. Fortin JD, Tolchin RB. Sacroiliac arthrograms and post-arthrography computerized tomography. Pain Physician. 2003;6(3):287-90.

81. Klauser A, De Zordo T, Feuchtner G, Sogner P, Schirmer M, Gruber $\mathrm{J}$, et al. Feasibility of ultrasound-guided sacroiliac joint injection considering sonoanatomic landmarks at two different levels in cadavers and patients. Arthritis Rheum. 2008;59(11):1618-24.

82. Migliore A, Bizzi E, Massafra U, Vacca F, Martin-Martin LS, Granata M, et al. A new technical contribution for ultrasound- 
guided injections of sacro-iliac joints. Eur Rev Med Pharmacol Sci. 2010;14(5):465-9.

83. Hartung W, Ross CJ, Straub R, Feuerbach S, Scholmerich J, Fleck $\mathrm{M}$, et al. Ultrasound-guided sacroiliac joint injection in patients with established sacroiliitis: precise IA injection verified by MRI scanning does not predict clinical outcome. Rheumatology (Oxford). 2010;49(8):1479-82.

84. Hansen H, Manchikanti L, Simopoulos TT, Christo PJ, Gupta S, Smith HS, et al. A systematic evaluation of the therapeutic ef fectiveness of sacroiliac joint interventions. Pain Physician. 2012;15(3):E247-78.

85. Simopoulos TT, Manchikanti L, Singh V, Gupta S, Hameed H, Diwan S, et al. A systematic evaluation of prevalence and diag nostic accuracy of sacroiliac joint interventions. Pain Physician. 2012;15(3):E305-44.

86. Rupert MP, Lee M, Manchikanti L, Datta S, Cohen SP. Evaluation of sacroiliac joint interventions: a systematic appraisal of the literature. Pain Physician. 2009;12(2):399-418.

87. Kapural L, Nageeb F, Kapural M, Cata JP, Narouze S, Mekhail N Cooled radiofrequency system for the treatment of chronic pain from sacroiliitis: the first case-series. Pain Pract. 2008;8(5):348-54

88. Stelzer W, Aiglesberger M, Stelzer D, Stelzer V. Use of cooled radiofrequency lateral branch neurotomy for the treatment of sacroiliac joint-mediated low back pain: a large case series. Pain Med. 2013;14(1):29-35

89. Patel N, Gross A, Brown L, Gekht G. A randomized, placebo-controlled study to assess the efficacy of lateral branch neurotomy for chronic sacroiliac joint pain. Pain Med. 2012;13(3):383-98.

90. Ferrante FM, King LF, Roche EA, Kim PS, Aranda M, Delaney LR, et al. Radiofrequency sacroiliac joint denervation for sacroiliac syndrome. Reg Anesth Pain Med. 2001;26(2):137-42.

91. Burnham RS, Yasui Y. An alternate method of radiofrequency neurotomy of the sacroiliac joint: a pilot study of the effect on pain function, and satisfaction. Reg Anesth Pain Med. 2007;32(1):12-9.

92. Vallejo R, Benyamin RM, Kramer J, Stanton G, Joseph NJ. Pulsed radiofrequency denervation for the treatment of sacroiliac joint syndrome. Pain Med. 2006;7(5):429-34.

93. Sacroiliac joint radiofrequency denervation using the Neurotherm Simplicity III system - a case series. In: Mehta V, Snidvongs S, Husband M editors. . 6th World Congress. 2012 Miami, Florida..

94. Videman $T$, Nurminen $M$. The occurrence of anular tears and their relation to lifetime back pain history: a cadaveric study using barium sulfate discography. Spine (Phila Pa 1976). 2004;29(23):2668-76.

95. Palmgren T, Gronblad M, Virri J, Kaapa E, Karaharju E. An immunohistochemical study of nerve structures in the anulus fibrosus of human normal lumbar intervertebral discs. Spine (Phila Pa 1976). 1999;24(20):2075-9.

96. Peng B, Wu W, Hou S, Li P, Zhang C, Yang Y. The pathogenesis of discogenic low back pain. J Bone Joint Surg Br. 2005;87(1):62-7.

97. Stout A. Discography. Phys Med Rehabil Clin NAm. 2010;21(4):859-67.

98. Berg S, Isberg B, Josephson A, Fallman M. The impact of discography on the surgical decision in patients with chronic low back pain. Spine J. 2012;12(4):283-91.

99. Carragee EJ, Alamin TF, Miller J, Grafe M. Provocative discography in volunteer subjects with mild persistent low back pain. Spine J. 2002;2(1):25-34.

100. Carragee EJ. Is lumbar discography a determinate of discogenic low back pain: provocative discography reconsidered. Curr Rev Pain. 2000;4(4):301-8.

101. Zucherman J, Derby R, Hsu K, Picetti G, Kaiser J, Schofferman J, et al. Normal magnetic resonance imaging with abnormal discography. Spine (Phila Pa 1976). 1988;13(12):1355-9.

102. Peng B, Hou S, Wu W, Zhang C, Yang Y. The pathogenesis and clinical significance of a high-intensity zone (HIZ) of lumbar intervertebral disc on MR imaging in the patient with discogenic low back pain. Eur Spine J. 2006;15(5):583-7.

103. Vanharanta H, Sachs BL, Spivey MA, Guyer RD, Hochschuler SH, Rashbaum RF, et al. The relationship of pain provocation to lumbar disc deterioration as seen by $\mathrm{CT} /$ discography. Spine (Phila Pa 1976). 1987;12(3):295-8.

104. Sachs BL, Vanharanta H, Spivey MA, Guyer RD, Videman T, Rash- baum RF, et al. Dallas discogram description. A new classification of CT/discography in low-back disorders. Spine (Phila Pa 1976). 1987;12(3):287-94.

105. Nachemson AL. Disc pressure measurements. Spine (Phila Pa 1976). 1981;6(1):93-7.

106. Lee SH, Derby R, Chen Y, Seo KS, Kim MJ. In vitro measurement of pressure in intervertebral discs and annulus fibrosus with and without annular tears during discography. Spine $J$. 2004;4(6):614-8

107. Quinnell RC, Stockdale HR, Harmon B. Pressure standardized lumbar discography. BrJ Radiol. 1980;53(635):1031-6.

108. Derby R, Howard MW, Grant JM, Lettice JJ, Van Peteghem PK, Ryan DP. The ability of pressure-controlled discography to predict surgical and nonsurgical outcomes. Spine (Phila Pa 1976). 1999;24(4):364-71.

109. Phillips H, Glazebrook JJ, Timothy J. Cauda equina compression post lumbar discography. Acta Neurochir (Wien). 2012; 154(6):1033-6.

110. Poynton AR, Hinman A, Lutz G, Farmer JC. Discography-induced acute lumbar disc herniation: a report of five cases. J Spinal Disord Tech. 2005;18(2):188-92.

111. Lopez WO, Vialle EN, Anillo CC, Guzmao M, Vialle LR. Clinical and radiological association with positive lumbar discography in patients with chronic low back pain. Evid Based Spine Care J. 2012;3(1):27-34

112. Derby R, Kim BJ, Lee SH, Chen Y, Seo KS, Aprill C. Comparison of discographic findings in asymptomatic subject discs and the negative discs of chronic LBP patients: can discography distinguish asymptomatic discs among morphologically abnormal discs? Spine J. 2005;5(4):389-94.

113. Manchikanti L, Glaser SE, Wolfer L, Derby R, Cohen SP. Systematic review of lumbar discography as a diagnostic test for chronic low back pain. Pain Physician. 2009;12(3):541-59.

114. Fritsch EW, Heisel J, Rupp S. The failed back surgery syndrome: reasons, intraoperative findings, and long-term results: a report of 182 operative treatments. Spine (Phila Pa 1976). 1996;21(5):626-33.

115. Deyo RA, Gray DT, Kreuter W, Mirza S, Martin BI. United States trends in lumbar fusion surgery for degenerative conditions. Spine (Phila Pa 1976). 2005;30(12):1441-5.

116. Katz JN. Lumbar spinal fusion. Surgical rates, costs, and complications. Spine (Phila Pa 1976). 1995;20(24 Suppl):78S-83S.

117. Atlas SJ, Keller RB, Wu YA, Deyo RA, Singer DE. Long-term outcomes of surgical and nonsurgical management of sciatica secondary to a lumbar disc herniation: 10 year results from the maine lumbar spine study. Spine (Phila Pa 1976). 2005;30(8):927-35

118. Hirsch JA, Singh V, Falco FJ, Benyamin RM, Manchikanti L. Automated percutaneous lumbar discectomy for the contained herniated lumbar disc: a systematic assessment of evidence. Pain Physician. 2009;12(3):601-20.

119. Singh V, Benyamin RM, Datta S, Falco FJ, Helm S2, Manchikanti L. Systematic review of percutaneous lumbar mechanical disc decompression utilizing Dekompressor. Pain Physician. 2009;12(3):589-99.

120. Manchikanti L, Derby R, Benyamin RM, Helm S, Hirsch JA. A systematic review of mechanical lumbar disc decompression with nucleoplasty. Pain Physician. 2009;12(3):561-72.

121. Lierz P, Alo KM, Felleiter P. Percutaneous lumbar discectomy using the Dekompressor system under CT-control. Pain Pract. 2009;9(3):216-20.

122. Singh V, Piryani C, Liao K. Evaluation of percutaneous disc decompression using coblation in chronic back pain with or without leg pain. Pain Physician. 2003;6(3):273-80.

123. Zhu H, Zhou XZ, Cheng MH, Shen YX, Dong QR. The efficacy of coblation nucleoplasty for protrusion of lumbar intervertebral disc at a two-year follow-up. Int Orthop. 2011;35(11):1677-82.

124. Singh V, Manchikanti L, Benyamin RM, Helm S, Hirsch JA. Percutaneous lumbar laser disc decompression: a systematic review of current evidence. Pain Physician. 2009;12(3):573-88.

125. Zhao XL, Fu ZJ, Xu YG, Zhao XJ, Song WG, Zheng H. Treatment of lumbar intervertebral disc herniation using C-arm fluoroscopy 
Patel VB et al.

guided target percutaneous laser disc decompression. Photomed Laser Surg. 2012;30(2):92-5.

126. Wegener B, Rieskamp K, Buttner A, Habiyambere V, von SchultzePellangahr C, Schaffer V, et al. Experimental evaluation of the risk of extradiscal thermal damage in intradiscal electrothermal therapy (IDET). Pain Physician. 2012;15(1):E99-E106.

127. Saal JA, Saal JS. Intradiscal electrothermal treatment for chronic discogenic low back pain: a prospective outcome study with minimum 1-year follow-up. Spine (Phila Pa 1976). 2000;25(20):2622-7.

128. Freeman BJ, Fraser RD, Cain CM, Hall DJ, Chapple DC. A randomized, double-blind, controlled trial: intradiscal electrothermal therapy versus placebo for the treatment of chronic discogenic low back pain. Spine (Phila Pa 1976). 2005;30(21):2369-77.

129. Pauza KJ, Howell S, Dreyfuss P, Peloza JH, Dawson K, Bogduk N. A randomized, placebo-controlled trial of intradiscal electrothermal therapy for the treatment of discogenic low back pain. Spine J. 2004;4(1):27-35.

130. Kvarstein G, Mawe L, Indahl A, Hol PK, Tennoe B, Digernes R, et al. A randomized double-blind controlled trial of intra-annular radiofrequency thermal disc therapy--a 12-month follow-up. Pain. 2009;145(3):279-86.

131. Kapural L, Mekhail N. Novel intradiscal biacuplasty (IDB) for the treatment of lumbar discogenic pain. Pain Pract. 2007;7(2):130-4.

132. Kapural L, Ng A, Dalton J, Mascha E, Kapural M, de la Garza M, et al. Intervertebral disc biacuplasty for the treatment of lumbar discogenic pain: results of a six-month follow-up. Pain Med. 2008;9(1):60-7.

133. Kapural L, Vrooman B, Sarwar S, Krizanac-Bengez L, Rauck R, Gilmore C, et al. A randomized, placebo-controlled trial of transdiscal radiofrequency, biacuplasty for treatment of discogenic lower back pain. Pain Med. 2013;14(3):362-73.

134. Cheng J, Pope JE, Dalton JE, Cheng O, Bensitel A. Comparative outcomes of cooled versus traditional radiofrequency ablation of the lateral branches for sacroiliac joint pain. Clin J Pain. 2013;29(2):132-7.

135. Helm Ii S, Deer TR, Manchikanti L, Datta S, Chopra P, Singh V, et al. Effectiveness of thermal annular procedures in treating discogenic low back pain. Pain Physician. 2012;15(3):E279-304.

136. US Food and Drug Administration.. 2015. Available from: http:| www.fda.gov/MedicalDevices/ProductsandMedicalProcedures/ DeviceApprovalsandClearances/PMAApprovals/ucm110773.htm.

137. Gupta A, Martindale T, Christo PJ. Intrathecal catheter granuloma associated with continuous sufentanil infusion. Pain Med. 2010;11(6):847-52.

138. Cabbell KL, Taren JA, Sagher O. Spinal cord compression by catheter granulomas in high-dose intrathecal morphine therapy: case report. Neurosurgery. 1998;42(5):1176-80.

139. Abejon D, del Saz JM, Ley L, Sanchez MR, del Pozo C. [Spinal granuloma in a patient receiving a spinal infusion of morphine and clonidine]. Rev Esp Anestesiol Reanim. 2009;56(6):380-4.

140. Bejjani GK, Karim NO, Tzortzidis F. Intrathecal granuloma after implantation of a morphine pump: case report and review of the literature. Surg Neurol. 1997;48(3):288-91.

141. Miele VJ, Price K, Bloomfield S, Hogg J, Bailes J. Intrathecal morphine therapy related granulomas: two case reports. $W V$ Med J. 2006;102(5):16-8.

142. Patel VB, Manchikanti L, Singh V, Schultz DM, Hayek SM, Smith HS. Systematic review of intrathecal infusion systems for longterm management of chronic non-cancer pain. Pain Physician. 2009;12(2):345-60.

143. Deer T, Chapple I, Classen A, Javery K, Stoker V, Tonder L, et al. Intrathecal drug delivery for treatment of chronic low back pain: report from the National Outcomes Registry for Low Back Pain. Pain Med. 2004;5(1):6-13.

144. Lara NJ, Teixeira MJ, Fonoff ET. Long term intrathecal infusion of opiates for treatment of failed back surgery syndrome. Acta Neurochir Suppl. 2011;108:41-7.

145. Anderson VC, Burchiel KJ. A prospective study of long-term intrathecal morphine in the management of chronic nonmalignant pain. Neurosurgery. 1999;44(2):289-300.

146. Kumar K, Kelly M, Pirlot T. Continuous intrathecal morphine treatment for chronic pain of nonmalignant etiology: long-term benefits and efficacy. Surg Neurol. 2001;55(2):79-86.

147. Rauck RL, Wallace MS, Burton AW, Kapural L, North JM. Intrathecal ziconotide for neuropathic pain: a review. Pain Pract. 2009;9(5):327-37.

148. Lynch SS, Cheng CM, Yee JL. Intrathecal ziconotide for refractory chronic pain. Ann Pharmacother. 2006;40(7-8):1293-300.

149. Pope JE, Deer TR. Ziconotide: a clinical update and pharmacologic review. Expert Opin Pharmacother. 2013;14(7):957-66.

150. Bala MM, Riemsma RP, Nixon J, Kleijnen J. Systematic review of the (cost-)effectiveness of spinal cord stimulation for people with failed back surgery syndrome. Clin J Pain. 2008;24(9):741-56.

151. Simpson EL, Duenas A, Holmes MW, Papaioannou D, Chilcott J. Spinal cord stimulation for chronic pain of neuropathic or ischaemic origin: systematic review and economic evaluation. Health Technol Assess. 2009;13(17):iii-1-154.

152. Hollingworth W, Turner JA, Welton NJ, Comstock BA, Deyo RA. Costs and cost-effectiveness of spinal cord stimulation (SCS) for failed back surgery syndrome: an observational study in a workers' compensation population. Spine (Phila Pa 1976). 2011;36(24):2076-83.

153. Rutten S, Komp M, Godolias G. [Spinal cord stimulation (SCS) using an 8-pole electrode and double-electrode system as minimally invasive therapy of the post-discotomy and post-fusion syndrome--prospective study results in 34 patients]. Z Orthop Ihre Grenzgeb. 2002;140(6):626-31.

154. Rainov NG, Heidecke V, Burkert W. Short test-period spinal cord stimulation for failed back surgery syndrome. Minim Invasive Neurosurg. 1996;39(2):41-4.

155. Sarubbo S, Latini F, Tugnoli V, Quatrale R, Granieri E, Cavallo MA. Spinal anesthesia and minimal invasive laminotomy for paddle electrode placement in spinal cord stimulation: technical report and clinical results at long-term followup. ScientificWorldJournal. 2012;2012:201053.

156. Deer T, Bowman R, Schocket SM, Kim C, Ranson M, Amirdelfan K, et al. The prospective evaluation of safety and success of a new method of introducing percutaneous paddle leads and complex arrays with an epidural access system. Neuromodulation. 2012;15(1):21-9.

157. Loge D, De Coster O, Washburn S. Technological innovation in spinal cord stimulation: use of a newly developed delivery device for introduction of spinal cord stimulation leads. Neuromodulation. 2012;15(4):392-401.

158. Kinfe TM, Schu S, Quack FJ, Wille C, Vesper J. Percutaneous implanted paddle lead for spinal cord stimulation: technical considerations and long-term follow-up. Neuromodulation. 2012;15(4):402-7.

159. Epstein LJ, Palmieri M. Managing chronic pain with spinal cord stimulation. Mt Sinai J Med. 2012;79(1):123-32.

160. Ohnmeiss DD, Rashbaum RF. Patient satisfaction with spinal cord stimulation for predominant complaints of chronic, intractable low back pain. Spine J. 2001;1(5):358-63.

161. Burchiel KJ, Anderson VC, Brown FD, Fessler RG, Friedman WA, Pelofsky S, et al. Prospective, multicenter study of spinal cord stimulation for relief of chronic back and extremity pain. Spine (Phila Pa 1976). 1996;21(23):2786-94.

162. de Vos CC, Dijkstra C, Lenders MW, Holsheimer J. Spinal cord stimulation with hybrid lead relieves pain in low back and legs. Neuromodulation. 2012;15(2):118-23.

163. Taylor RJ, Taylor RS. Spinal cord stimulation for failed back surgery syndrome: a decision-analytic model and cost-effectiveness analysis. Int JTechnol Assess Health Care. 2005;21(3):351-8.

164. North RB, Kidd DH, Farrokhi F, Piantadosi SA. Spinal cord stimulation versus repeated lumbosacral spine surgery for chronic pain: a randomized, controlled trial. Neurosurgery. 2005;56(1):98-106.

165. North RB, Kidd DH, Piantadosi S. Spinal cord stimulation versus reoperation for failed back surgery syndrome: a prospective, randomized study design. Acta Neurochir Suppl. 1995;64:106-8.

166. Frey ME, Manchikanti L, Benyamin RM, Schultz DM, Smith HS, Cohen SP. Spinal cord stimulation for patients with failed back surgery syndrome: a systematic review. Pain Physician. 2009;12(2):379-97.

167. Sharan A, Cameron T, Barolat G. Evolving patterns of spinal cord 
stimulation in patients implanted for intractable low back and leg pain. Neuromodulation. 2002;5(3):167-79.

168. Abejon D, Deer T, Verrills P. Subcutaneous stimulation: how to assess optimal implantation depth. Neuromodulation. 2011;14(4):343-7.

169. Verrills P, Vivian D, Mitchell B, Barnard A. Peripheral nerve field stimulation for chronic pain: 100 cases and review of the literature. Pain Med. 2011;12(9):1395-405.

170. Bernstein CA, Paicius RM, Barkow SH, Lempert-Cohen C. Spinal cord stimulation in conjunction with peripheral nerve field stimulation for the treatment of low back and leg pain: a case series. Neuromodulation. 2008;11(2):116-23.

171. Mironer YE, Hutcheson JK, Satterthwaite JR, LaTourette PC. Prospective, two-part study of the interaction between spinal cord stimulation and peripheral nerve field stimulation in patients with low back pain: development of a new spinal-peripheral neurostimulation method. Neuromodulation. 2011;14(2):151-4.

172. Reverberi C, Dario A, Barolat G. Spinal cord stimulation (SCS) in conjunction with peripheral nerve field stimulation (PNfS) for the treatment of complex pain in failed back surgery syndrome (FBSS). Neuromodulation. 2013;16(1):78-82.

173. Yakovlev AE, Resch BE, Yakovleva VE. Peripheral nerve field stimu- lation in the treatment of postlaminectomy syndrome after multilevel spinal surgeries. Neuromodulation. 2011;14(6):534-8.

174. Burgher AH, Huntoon MA, Turley TW, Doust MW, Stearns LJ. Subcutaneous peripheral nerve stimulation with inter-lead stimulation for axial neck and low back pain: case series and review of the literature. Neuromodulation. 2012;15(2):100-6.

175. Cuellar JM, Alataris K, Walker A, Yeomans DC, Antognini JF. Effect of high-frequency alternating current on spinal afferent nociceptive transmission. Neuromodulation. 2013;16(4):318-27.

176. Van Buyten JP, Al-Kaisy A, Smet I, Palmisani S, Smith T. Highfrequency spinal cord stimulation for the treatment of chronic back pain patients: results of a prospective multicenter European clinical study. Neuromodulation. 2013;16(1):59-65.

177. Tiede J, Brown L, Gekht G, Vallejo R, Yearwood T, Morgan D. Novel spinal cord stimulation parameters in patients with predominant back pain. Neuromodulation. 2013;16(4):370-5.

178. Perruchoud C, Eldabe S, Batterham AM, Madzinga G, Brookes M, Durrer A, et al. Analgesic efficacy of high-frequency spinal cord stimulation: a randomized double-blind placebo-controlled study. Neuromodulation. 2013;16(4):363-9.

179. Kelsey JL, White A3. Epidemiology and impact of low-back pain. Spine (Phila Pa 1976). 1980;5(2):133-42. 